\title{
Evolution of the CD163 family and its relationship to the bovine gamma delta T cell co-receptor WC1
}

\author{
Carolyn TA Herzig' ${ }^{1}$, Ray W Waters², Cynthia L Baldwin and Janice C Telfer*1
}

\begin{abstract}
Background: The scavenger receptor cysteine rich (SRCR) domain is an ancient and conserved protein domain. CD163 and WC1 molecules are classed together as group B SRCR superfamily members, along with Spa, CD5 and CD6, all of which are expressed by immune system cells. There are three known types of CD163 molecules in mammals, CD163A (M130, coded for by CD163), CD163b (M160, coded for by CD163L1) and CD163c-a (CD163L1 or SCART), while their nearest relative, WC1, is encoded by a multigene family so far identified in the artiodactyl species of cattle, sheep, and pigs.

Results: We annotated the bovine genome and identified genes coding for bovine CD163A and CD163C-a but found no evidence for CD163b. Bovine CD163A is widely expressed in immune cells, whereas CD163c-a transcripts are enriched in the WC1 $+\gamma \delta$ T cell population. Phylogenetic analyses of the CD163 family genes and WC1 showed that CD163c-a is most closely related to WC1 and that chicken and platypus have WC1 orthologous genes, previously classified as among their CD163 genes.

Conclusion: Since it has been shown that WC1 plays an important role in the regulation of $\gamma \delta$ T cell responses in cattle, which, like chickens, have a high percentage of $\gamma \delta$ T cells in their peripheral blood, CD163c-a may play a similar role, especially in species lacking WC1 genes. Our results suggest that gene duplications resulted in the expansion of CD163c-a-like and WC1-like molecules. This expanded repertoire was retained by species known as " $\gamma \delta \mathrm{T}$ cell high", but homologous SRCR molecules were maintained by all mammals.
\end{abstract}

\section{Background}

The CD163 family includes genes encoding CD163A (also known as M130, HbSR, and coded for by CD163), CD163b (also known as M160, and coded for by CD163L1) and CD163c- $\alpha$ (also known as CD163L1 and SCART). This family is a subset of the scavenger receptor cysteine-rich (SRCR) super-family, an ancient super-family defined by the presence of 100-110 amino acid domains [1]. Members of the CD163 family are group B SRCR proteins distinguished by the 6-8 cysteines in their SRCR domains resulting in 3-4 disulfide bonds; in comparison, group A SRCR proteins have only 6 cysteines and 3 disulfide bonds in their SRCR domains. SRCR domains, like Ig domains or epidermal growth factor-like domains, are thought to be involved in protein-protein

\footnotetext{
* Correspondence: telfer@vasci.umass.edu

1 University of Massachusetts Amherst, Department of Veterinary and Animal Sciences, Paige Laboratory, Amherst, MA 01003, USA

Full list of author information is available at the end of the article
}

interactions, although the known ligands of these domains vary widely.

CD163A is a receptor for haptoglobin-hemoglobin complexes, and is inducibly expressed on monocytes, macrophages and a subpopulation of hematopoietic progenitors [2-6]. CD163A protects against oxidative damage by mediating the endocytosis of haptoglobinhemoglobin complexes [7]. Ligation of CD163A by haptoglobin-hemoglobin complexes induces the secretion of the anti-inflammatory cytokine IL-10 [8]. In addition, proteolytically-cleaved CD163A shed into serum inhibits phorbol ester-induced $\mathrm{T}$ cell proliferation [9]. The third SRCR domain of CD163A mediates its interaction with haptoglobin and TWEAK (TNF-like weak inducer of apoptosis) [10,11]. CD163A interacts with a molecule expressed on erythroblasts and with bacteria via its second SRCR domain [12,13]. The related group B SRCR molecule CD6 also binds to bacteria via one or more of its SRCR domains, through interactions with the bacterial 
non-peptiditic products lipoteichoic acid (LTA) and lipopolysaccharide (LPS) [14].

CD163A transcripts display alternative splicing of the extracellular and cytoplasmic coding regions, potentially increasing the diversity of its function $[15,16]$. The CD163A form with a short cytoplasmic domain predominates and mediates ligand internalization and degradation but the function of the CD163A form with a long cytoplasmic domain is unknown [17]. Cross-linking of CD163A induces inositol triphosphate and cytokine production [18]. The CD163A cytoplasmic domain is phosphorylated by casein kinase II and protein kinase $C-\alpha$ $(\mathrm{PKC}-\alpha)$ and these phosphorylation events are tied to cytokine production induced by CD163A cross-linking [19]. Casein kinase II activity and anti-inflammatory cytokine production in macrophages is stimulated by CD163A binding to only one of the two alleles of haptoglobin, although both bind to CD163A with high affinity [20]. The non-stimulatory haptoglobin allele is correlated with increased susceptibility to cardiovascular disease $[21,22]$.

CD163b is also expressed on macrophages, with two cytoplasmic domain variants of 71 and 39 amino acids, resulting from alternative splicing [23]. Little is known about the function or ligand of CD163b. Thus far, the gene encoding CD163b has only been found in the genomes of primates and the horse.

Unlike CD163A, which is encoded by one gene across eutherian mammals, several species possess multiple genes encoding CD163c- $\alpha$ molecules. There are two CD163c- $\alpha$ genes in mice: SCART1 and SCART2. SCART1 is expressed in the lymph node, trachea and lung; SCART2 is expressed on murine $\gamma \delta \mathrm{T}$ cells that secrete IL-17 [24,25]. The presence of multiple genes encoding the SRCR transmembrane receptor CD163c- $\alpha$ is similar to that of another set of group B SRCR proteins, WC1. Genes encoding WC1 have been found in the artiodactyl species cattle (Bos taurus), sheep (Ovis aries) and swine (Sus scrofa) [26-30]. WC1 molecules are encoded by a family of fifteen genes in the bovine and, like SCART2, are expressed on $\gamma \delta$ T cells [26,27,30-34]. WC1 contributes to the $\gamma \delta \mathrm{T}$ cell response to Leptospira (Wang F, Herzig CTA, Hsu H, Chen C, Baldwin CL, Telfer JC: Scavenger receptor WC1 contributes to the gamma delta $\mathrm{T}$ cell responses to Leptospira, submitted) and WC1-mediated potentiation of $\mathrm{T}$ cell activation requires the phosphorylation of a tyrosine in its cytoplasmic domain [35]. Moreover, expression of different molecular forms of WC1 on bovine $\gamma \delta \mathrm{T}$ cells is correlated with differential response to bacteria, suggesting that WC1 functions as a pattern recognition molecule similar to the related SRCR molecules CD163A, CD5, CD6, Spa and DMBT1 $[13,14,36-40]$. No WC1 homologues have thus far been identified in human or murine $\gamma \delta \mathrm{T}$ cells, leading to the question of whether CD163 family members, particularly CD163c- $\alpha$ molecules, have evolved to serve functions equivalent to $\mathrm{WC} 1$ in mammals other than the artiodactyls.

In our recent annotation of the bovine genome we found the gene encoding CD163A embedded within the region coding for $\mathrm{WC1}$ genes [31]. To determine the extent of the CD163 family in artiodactyls, we annotated the bovine genome to identify CD163 family genes in cattle. We found genes encoding both CD163A and CD163c- $\alpha$, but not CD163b, and evaluated their expression profile in $\gamma \delta \mathrm{T}$ cells and other tissues. Incorrect assignment of genes belonging to the CD163 and the WC1 families from many species has created substantial confusion in naming and categorizing these genes. To appropriately categorize the genes identified both by us and by others, we undertook phylogenetic analyses of CD163 and WC1 family members. Here, we show the relationship between CD163A, CD163c- $\alpha$ and WC1 family receptors, all expressed in $\gamma \delta \mathrm{T}$ cells of artiodactyls, that WC1 orthologues are present in the chicken and platypus, and correlate the conservation over evolutionary time of a diverse array of these receptors with the presence of a high level of $\gamma \delta \mathrm{T}$ cells in the peripheral blood.

\section{Results}

\section{Exon-intron structure of bovine CD163 family members}

Annotation of the bovine genome indicated that cattle have a gene coding for CD163A, which was found on chromosome 5 within one of the two loci coding for the large WC1 family of genes [31]. A gene coding for bovine CD163c- $\alpha$ was also found but could not be placed in the bovine genome due to insufficient scaffolding. Schematics of the exon-intron structure of these two genes are shown in Fig. 1. Both CD163A and CD163c- $\alpha$ contain a cytoplasmic domain coded for by two exons, one of which also encodes the transmembrane domain. Interestingly, like WC1, both CD163A and CD163c- $\alpha$ contain an exon that encodes interdomain sequence (Fig. 1, ID) [31]. The gene encoding CD163A spans approximately $30 \mathrm{kbp}$; that of CD163c- $\alpha$ spans approximately $12 \mathrm{kbp}$.

The CD163c- $\alpha$ amino acid sequence generated by automated prediction lacked a transmembrane region that was correlated with a gap in the genomic sequence at the expected location of the exon encoding the transmembrane domain (Fig. 1B). We investigated whether bovine CD163c- $\alpha$ has a transmembrane domain by amplifying and sequencing cDNA template from peripheral blood mononuclear cells using primers designed from known sequences in the genomic sequence, which bracketed the putative transmembrane region. We obtained transmembrane domain sequence in the same frame as known sequence upstream and downstream (Fig. 2B), indicating 
A

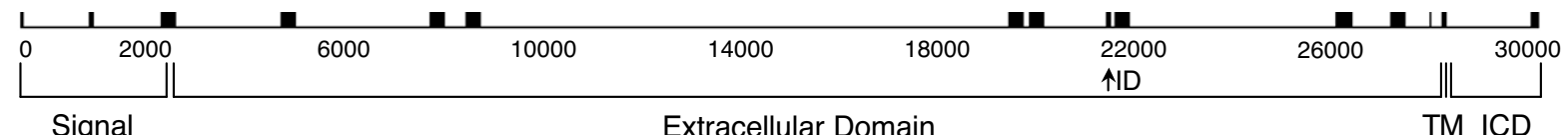

Sequence

\begin{tabular}{l|llllll} 
SRCR & II & III IV & V VI VII & VIII IX \\
Domain
\end{tabular}

B

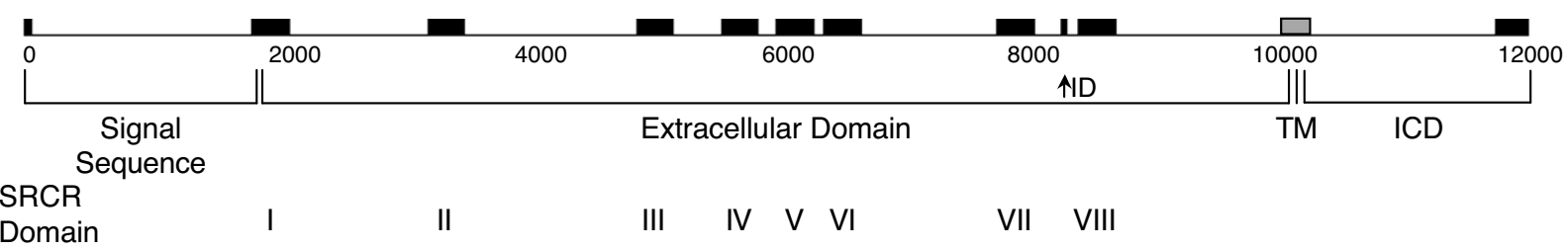

Figure 1 Schematic representation of bovine CD163 exon-intron structure. Exon-intron structures of (A) CD163A and (B) CD163C-a were determined based on annotation of the CD163 genes in the bovine genome assembly Btau_3.1. Proposed placement of the exon encoding CD163c-a transmembrane region is shown in grey and could not be confirmed due to a gap in the genomic sequence assembly. SRCR domain numbers are indicated by roman numerals. Scale is shown in base pair increments beneath the schematic. Abbreviations are as follows: ID, interdomain sequence; TM, transmembrane region; ICD, intracytoplasmic domain.

that the bovine CD163c- $\alpha$ is a transmembrane receptor. The bovine homologue of the human gene encoding CD163b was not found in the bovine genome assembly Btau 3.1, which could reflect its absence or a relatively large gap in the sequenced bovine genome.

\section{Bovine CD163 sequences}

Based on the manual annotation of the bovine CD163c- $\alpha$ and CD163A gene sequences (Fig. 1), we designed primers to amplify CD163A and CD163c- $\alpha$ transcripts. Deduced amino acid sequences based on the obtained cDNA sequence of CD163A (Fig. 2A) and on both the annotated genomic sequence and obtained cDNA sequence (shaded) of CD163c- $\alpha$ (Fig. 2B) were used to evaluate their predicted protein structures. Bovine CD163A has nine SRCR domains and bovine CD163c- $\alpha$ has eight SRCR domains in their extracellular regions, which are underlined in the predicted protein (Fig. 2). Most of the SRCR domains conform to the eight-cysteine consensus of SRCR group B. The exceptions are the eighth SRCR domain of bovine CD163A and the fifth SRCR domain of bovine CD163c- $\alpha$. These SRCR domains lack the second and seventh cysteines, which form a disulfide bond in most, but not all, other SRCR group B domains. Estimates of the evolutionary divergence between SRCR domain amino acid sequences confirm that bovine CD163A is most similar to human CD163A (Table 1) and that bovine CD163c- $\alpha$ is most similar to human CD163c- $\alpha$ (Table 2) in both the order of SRCR domains and sequence identity. Bovine CD163A is identical to human CD163A in its SRCR domain organization, and highly similar in its sequence with $82 \%$ overall sequence identity. Bovine CD163c- $\alpha$ is identical to human CD163c- $\alpha$ in its SRCR domain organization and $68 \%$ identical in overall sequence. The evolutionary divergence between bovine CD163A or bovine CD163c- $\alpha$ SRCR domains and bovine WC1 SRCR domains is greater (Table 3), indicating that the genes we have identified as bovine CD163A or bovine CD163c- $\alpha$ are not WC1 genes. The sequences of the cytoplasmic domains of CD163c- $\alpha$ and CD163A from cattle do not exhibit significant sequence identity to each other (data not shown), although they contain the tyrosine-based motifs of YEDI and YREM respectively.

\section{Expression profiles of bovine CD163A and CD163c-a}

A variety of tissues were examined for expression of bovine CD163 transcripts including mesenteric lymph node (MLN), lung, intestinal intraepithelial lymphocytes (IELs, containing approximately $20 \% \gamma \delta$ T cells, data not shown) and peripheral blood mononuclear cells (PBMC). PBMC were evaluated both as ex vivo cells and following 
A

MVLHDNSGSAGFKRCSVHFGPFTL AVVSVLYACLVTSALGGTDKELRLVAGQTKESGRVEVKVQEEWGTV70

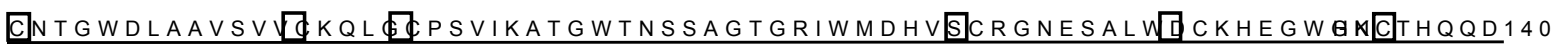
VGVTCSDGSDLEMRLMNGGNRESRIEIKFQGQWGTVCDPNFNLDH ASVV四KQLG GGSAVSFSGSANFGE 210

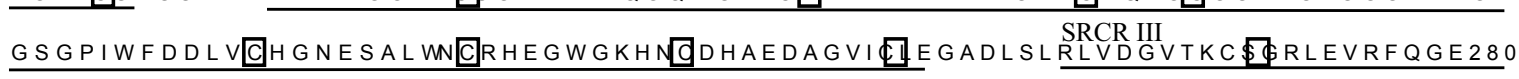
WGTVCDDGWDSHDA V A CQQL G]PTAITAVGRVNASEGTGHIWLDSVSCQGHESAVW QRHHEWGKHYCN 350 HNEDAGVT@DGSDLELRLKGGGSRCA@ VEVEIQKLIGKV DDRSWGLKEADVVCKQLG GGSALRTSYQV4 20 YSKIQATNTWLFLNNCNGNETSIWDCHNWQWGGLSCEHYH EAKVTC]SAHREPRLVGGDIPCS GRVEVKHG 490

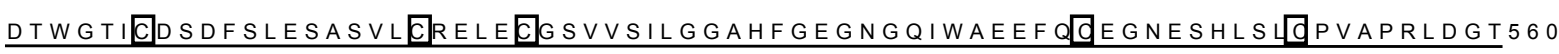

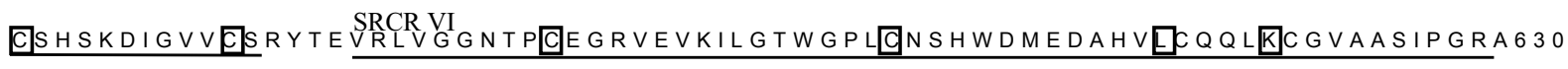
PFGKGSGQPWRHMF日C TGTEQHM G回CPVTALGA 四CPEGQVAS 日CSGNRSQTLYPCNSSSSDPESSVVL 700

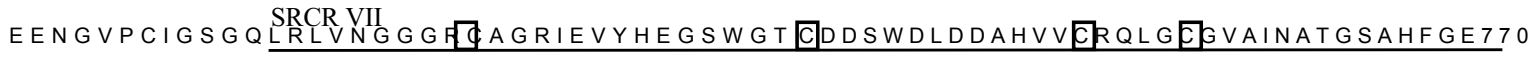

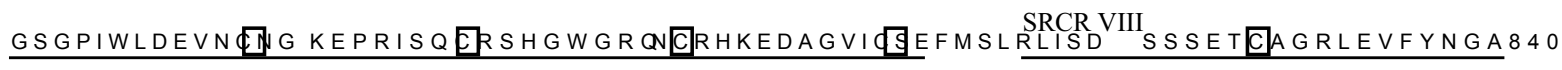
WGSVGKSDMSATTVGV凹RQL包TDKGSIRPAPSDKVENRYMWVDN 目CPKGPETLWCPSSPWKRRLAS 910 PSEETWITCADKIRLQEGTTN\&\$GRVEVWHGGSWGT CDDSWDLNDAQVVCRQLGCGLALEAG KEAAFGQ980 GTGPIWLNEVKCKGNESSLW 四PARSWGHS回CGHKEDAS 田CSEIAESKGSVKAAGHSSTVALGILGVIL 1050 LAFLIATLLWIQRRRQRQRL AVSSRGENSVHEIQYREMNSCLKADDLDLYNSSGLWVLRGSIALGFRVT 1120 A AEAERHST * 1130

\section{$B$} SRCR I

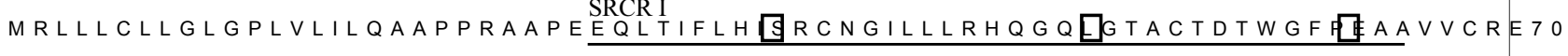
LDCGAPLGAPKEVPGPEIMAQPWLHGLT QQGNESSIQE耳ALGAWGPRERPHDWVPA MMCMGGLEVVIKLV 140 GGRS म VLNCKIDWANFKPCVSNDEVIDSGHTEARLVGGEHSCAGRLEVRRGLTWGTVDADLDLATAHVVRELQ 280 CGAAVSTPQGAHFGQGPGLVWAEAFRCAGNESLLFECPREPGHRCGHGQDAGRRCSEFRLVNGSSACEGR350 VELQVQGAWAP里AAHWDLADATV WHQLDCGNAVAPPGGHFGGGASAPWPDEVHCVGTEPYLMSCAVS 420

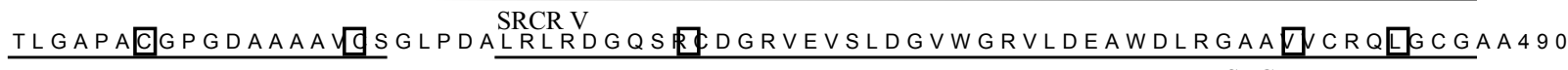
ERAYEAAAPARGAVPLGLSRVRⒶGTEPRLTRNVSAAALVSAGASRDAGV凹SGSLQVRLAAGPGQCAG 560

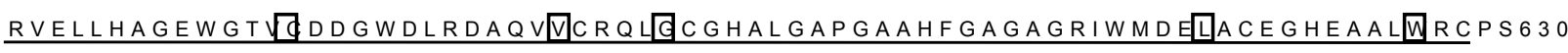
SRCR VII

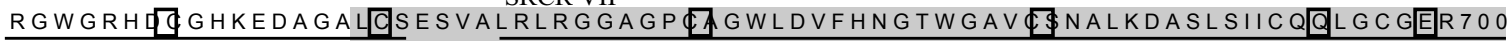

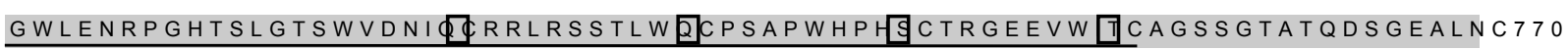

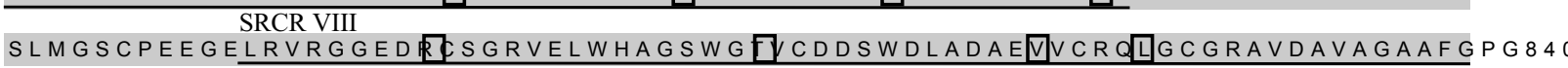
SLMGSCPEEGELRVRGGEDRPS GRVELWHAGSWGDCDDSWDLADAEVVVROLGCGRAVDAVAGAAFG

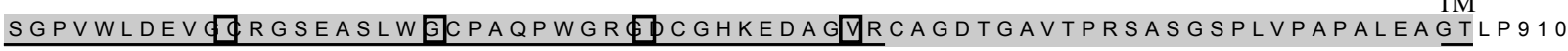
MALGLALGTLLLVTSLVLGARWFRGRDACRGSGMSGSLPSEGVYEDIGVATAGEKDEAAGAAAAALEEE 980

YDDVAEPEPEEGDAEEGALLSPTGAQLCVVASTVLLLLYWCYAQGSGPPSPYI* 1034

Figure 2 Amino acid sequences of bovine CD163. Translated amino acid sequence, based on CDNA sequences for (A) CD163A and based on annotated and determined CDNA (shaded) sequences for (B) CD163c-a. Individual SRCR domains, identified by comparison to consensus group B SRCR domain sequence, are underlined, domain numbers are indicated by roman numerals, and cysteines are boxed. Putative transmembrane regions (TM) were determined by the DAS transmembrane prediction server and are also underlined [70] 
Table 1: Estimates of evolutionary divergence between human CD163A, bovine CD163A and bovine CD163C-a SRCR domains

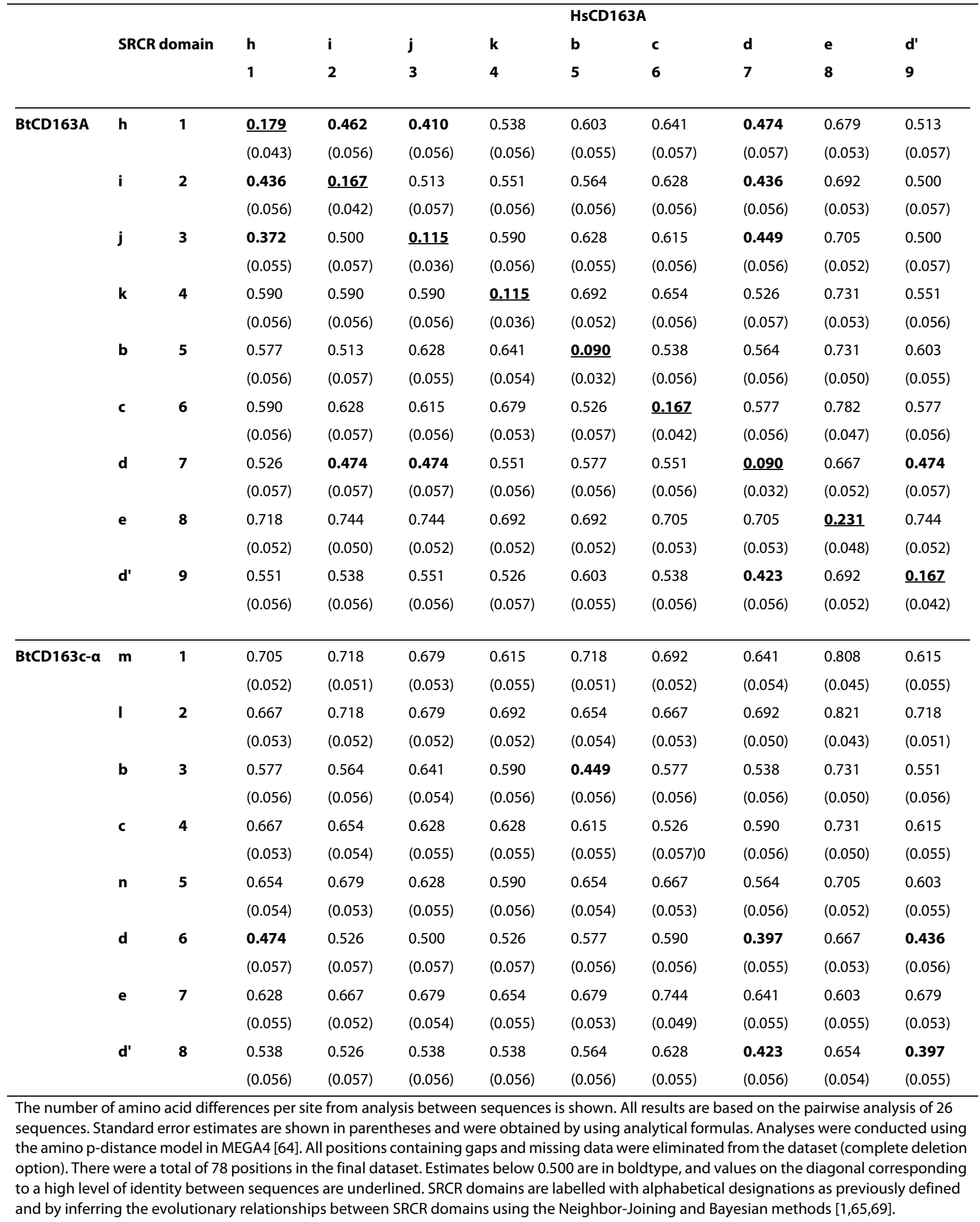


Table 2: Estimates of evolutionary divergence between human CD163c- $a$, bovine CD163A and bovine CD163C- $a$ SRCR domains

\begin{tabular}{|c|c|c|c|c|c|c|c|c|c|c|}
\hline & & \multicolumn{9}{|c|}{ HsCD163c-a } \\
\hline & \multicolumn{2}{|c|}{ SRCR domain } & $\begin{array}{l}m \\
1\end{array}$ & $\begin{array}{l}1 \\
2\end{array}$ & $\begin{array}{l}\text { b } \\
3\end{array}$ & $\begin{array}{l}c \\
4\end{array}$ & $\begin{array}{l}n \\
5\end{array}$ & $\begin{array}{l}d \\
6\end{array}$ & $\begin{array}{l}\text { e } \\
7\end{array}$ & $\begin{array}{l}\text { d' } \\
8\end{array}$ \\
\hline \multirow[t]{18}{*}{ BtCD163A } & $\mathbf{h}$ & 1 & 0.577 & 0.692 & 0.590 & 0.641 & 0.641 & 0.500 & 0.628 & 0.513 \\
\hline & & & $(0.056)$ & $(0.052)$ & $(0.056)$ & $(0.054)$ & $(0.054)$ & $(0.057)$ & $(0.055)$ & $(0.057)$ \\
\hline & $\mathbf{i}$ & 2 & 0.590 & 0.731 & 0.551 & 0.628 & 0.667 & 0.462 & 0.641 & 0.474 \\
\hline & & & $(0.056)$ & $(0.050)$ & $(0.056)$ & $(0.055)$ & $(0.053)$ & $(0.056)$ & $(0.054)$ & $(0.057)$ \\
\hline & $\mathbf{j}$ & 3 & 0.615 & 0.679 & 0.654 & 0.628 & 0.641 & 0.474 & 0.628 & 0.526 \\
\hline & & & $(0.055)$ & $(0.053)$ & $(0.054)$ & $(0.055)$ & $(0.054)$ & $(0.057)$ & $(0.055)$ & $(0.057)$ \\
\hline & $\mathbf{k}$ & 4 & 0.551 & 0.654 & 0.615 & 0.692 & 0.628 & 0.577 & 0.679 & 0.590 \\
\hline & & & $(0.056)$ & $(0.054)$ & $(0.055)$ & $(0.052)$ & $(0.055)$ & $(0.056)$ & $(0.053)$ & $(0.056)$ \\
\hline & b & 5 & 0.654 & 0.667 & 0.462 & 0.590 & 0.679 & 0.538 & 0.692 & 0.564 \\
\hline & & & $(0.054)$ & $(0.053)$ & $(0.056)$ & $(0.056)$ & $(0.053)$ & $(0.056)$ & $(0.052)$ & $(0.056)$ \\
\hline & c & 6 & 0.654 & 0.654 & 0.551 & 0.500 & 0.667 & 0.590 & 0.731 & 0.615 \\
\hline & & & $(0.054)$ & $(0.054)$ & $(0.056)$ & $(0.057)$ & $(0.053)$ & $(0.056)$ & $(0.050)$ & $(0.055)$ \\
\hline & d & 7 & 0.615 & 0.615 & 0.551 & 0.590 & 0.577 & 0.372 & 0.679 & 0.436 \\
\hline & & & $(0.055)$ & $(0.055)$ & $(0.056)$ & $(0.056)$ & $(0.056)$ & $(0.055)$ & $(0.053)$ & $(0.056)$ \\
\hline & e & 8 & 0.718 & 0.795 & 0.744 & 0.756 & 0.679 & 0.654 & 0.577 & 0.692 \\
\hline & & & $(0.051)$ & $(0.046)$ & $(0.049)$ & $(0.049)$ & $(0.053)$ & $(0.054)$ & $(0.056)$ & $(0.052)$ \\
\hline & $d^{\prime}$ & 9 & 0.513 & 0.679 & 0.526 & 0.590 & 0.590 & 0.436 & 0.667 & 0.410 \\
\hline & & & $(0.057)$ & $(0.053)$ & $(0.057)$ & $(0.056)$ & $(0.056)$ & $(0.056)$ & $(0.053)$ & $(0.056)$ \\
\hline \multirow[t]{16}{*}{ BtCD163c-a } & $\mathbf{m}$ & 1 & $\underline{0.462}$ & 0.641 & 0.667 & 0.718 & 0.692 & 0.654 & 0.808 & 0.667 \\
\hline & & & $(0.056)$ & $(0.054)$ & $(0.053)$ & $(0.051)$ & $(0.052)$ & $(0.054)$ & $(0.045)$ & $(0.053)$ \\
\hline & I & 2 & 0.705 & $\underline{0.577}$ & 0.692 & 0.705 & 0.744 & 0.731 & 0.756 & 0.744 \\
\hline & & & $(0.052)$ & $(0.056)$ & $(0.052)$ & $(0.052)$ & $(0.049)$ & $(0.050)$ & $(0.049)$ & $(0.049)$ \\
\hline & b & 3 & 0.603 & 0.692 & $\underline{0.167}$ & 0.577 & 0.679 & 0.526 & 0.667 & 0.526 \\
\hline & & & $(0.055)$ & $(0.052)$ & $(0.042)$ & $(0.056)$ & $(0.053)$ & $(0.057)$ & $(0.053)$ & $(0.057)$ \\
\hline & c & 4 & 0.603 & 0.667 & 0.590 & $\underline{0.218}$ & 0.641 & 0.615 & 0.756 & 0.615 \\
\hline & & & $(0.055)$ & $(0.053)$ & $(0.056)$ & $(0.047)$ & $(0.054)$ & $(0.055)$ & $(0.049)$ & $(0.055)$ \\
\hline & $\mathbf{n}$ & 5 & 0.615 & 0.641 & 0.603 & 0.654 & 0.231 & 0.538 & 0.731 & 0.538 \\
\hline & & & $(0.055)$ & $(0.054)$ & $(0.055)$ & $(0.054)$ & $(0.048)$ & $(0.056)$ & $(0.050)$ & $(0.056)$ \\
\hline & d & 6 & 0.538 & 0.667 & 0.538 & 0.551 & 0.590 & $\underline{0.218}$ & 0.654 & 0.410 \\
\hline & & & $(0.056)$ & $(0.053)$ & $(0.056)$ & $(0.056)$ & $(0.056)$ & $(0.047)$ & $(0.054)$ & $(0.056)$ \\
\hline & e & 7 & 0.692 & 0.731 & 0.641 & 0.718 & 0.744 & 0.615 & $\underline{0.179}$ & 0.654 \\
\hline & & & $(0.052)$ & $(0.050)$ & $(0.054)$ & $(0.051)$ & $(0.049)$ & $(0.055)$ & $(0.043)$ & $(0.054)$ \\
\hline & d' $^{\prime}$ & 8 & 0.551 & 0.692 & 0.487 & 0.577 & 0.564 & 0.423 & 0.628 & $\underline{0.141}$ \\
\hline & & & $(0.056)$ & $(0.052)$ & $(0.057)$ & $(0.056)$ & $(0.056)$ & $(0.056)$ & $(0.055)$ & $(0.039)$ \\
\hline
\end{tabular}

Analyses were conducted as described in Table 1. 
Table 3: Estimates of evolutionary divergence between bovine archetypal WC1.1, bovine CD163A and bovine CD163C- $a$ SRCR domains

\begin{tabular}{|c|c|c|c|c|c|c|c|c|}
\hline & & & \multicolumn{6}{|c|}{ BtWC1.1 } \\
\hline & \multicolumn{2}{|c|}{ SRCR domain } & \multirow{2}{*}{$\begin{array}{l}a \\
1\end{array}$} & \multirow{2}{*}{$\begin{array}{l}b \\
2,7\end{array}$} & \multirow{2}{*}{$\begin{array}{l}c \\
3,8\end{array}$} & \multirow{2}{*}{$\begin{array}{l}\text { d } \\
4,6,9\end{array}$} & \multirow{2}{*}{$\begin{array}{l}\text { e } \\
5,10\end{array}$} & \multirow{2}{*}{$\begin{array}{l}d^{\prime} \\
11\end{array}$} \\
\hline & & & & & & & & \\
\hline \multirow[t]{9}{*}{ BtCD163A } & $\mathbf{h}$ & 1 & $0.551(0.056)$ & $0.667,0.654(0.053,0.054)$ & $0.641,0.654(0.054,0.054)$ & $\mathbf{0 . 4 6 2}, \mathbf{0 . 4 6 2}, 0.500(0.056,0.056,0.057)$ & $0.705,0.692(0.052,0.052)$ & $0.500(0.057)$ \\
\hline & $\mathbf{i}$ & 2 & $0.526(0.057)$ & $0.577,0.564(0.056,0.056)$ & $0.590,0.615(0.056,0.055)$ & $\mathbf{0 . 4 3 6}, \mathbf{0 . 4 1 0} \mathbf{0 . 4 3 6}(0.056,0.056,0.056)$ & $0.705,0.667(0.052,0.053)$ & $0.487(0.057)$ \\
\hline & $\mathbf{j}$ & 3 & $0.500(0.057)$ & $0.679,0.654(0.053,0.054)$ & $0.654,0.679(0.054,0.053)$ & $\mathbf{0 . 4 4 9}, \mathbf{0 . 4 4 9}, \mathbf{0 . 4 4 9}(0.056,0.056,0.056)$ & $0.705,0.705(0.052,0.052)$ & $0.500(0.057)$ \\
\hline & $\mathbf{k}$ & 4 & $0.564(0.056)$ & $0.654,0.641(0.054,0.054)$ & $0.615,0.615(0.055,0.055)$ & $0.564,0.551,0.577(0.056,0.056,0.056)$ & $0.705,0.692(0.052,0.052)$ & $0.500(0.057)$ \\
\hline & b & 5 & $0.551(0.056)$ & $\mathbf{0 . 4 4 9 ,} \mathbf{0 . 4 3 6}(0.056,0.056)$ & $0.577,0.603(0.056,0.055)$ & $0.526,0.590,0.513(0.057,0.056,0.054)$ & $0.718,0.692(0.051,0.052)$ & $0.538(0.056)$ \\
\hline & c & 6 & $0.590(0.056)$ & $0.615,0.590(0.055,0.056)$ & $0.513,0.538(0.057,0.056)$ & $0.513,0.590,0.526(0.057,0.056,0.057)$ & $0.769,0.731(0.048,0.050)$ & $0.603(0.055)$ \\
\hline & d & 7 & $\mathbf{0 . 4 8 7}(0.057)$ & $0.641,0.628(0.054,0.055)$ & $0.590,0.603(0.056,0.055)$ & $\mathbf{0 . 2 1 8}, \mathbf{0 . 3 2 1}, \mathbf{0 . 2 1 8}(0.047,0.053,0.047)$ & $0.667,0.641(0.053,0.054)$ & $0.474(0.057)$ \\
\hline & e & 8 & $0.744(0.049)$ & $0.731,0.705(0.050,0.052)$ & $0.731,0.731(0.050,0.050)$ & $0.718,0.744,0.692(0.051,0.049,0.052)$ & $0.513,0.500(0.057,0.057)$ & $0.692(0.052)$ \\
\hline & $\mathbf{d}^{\prime}$ & 9 & $0.526(0.057)$ & $0.615,0.590(0.055,0.056)$ & $0.590,0.590(0.056,0.056)$ & $\mathbf{0 . 4 2 3}, \mathbf{0 . 4 3 6}, \mathbf{0 . 3 9 7}(0.056,0.056,0.055)$ & $0.679,0.667(0.053,0.053)$ & $0.359(0.054)$ \\
\hline \multirow[t]{5}{*}{ BtCD163c-a } & $\mathbf{m}$ & 1 & $0.654(0.054)$ & $0.756,0.731(0.049 .0 .050)$ & $0.679,0.679(0.053,0.053)$ & $0.654,0.667,0.654(0.054,0.053,0.054)$ & $0.795,0.769(0.046,0.048)$ & $0.628(0.055)$ \\
\hline & $\mathbf{I}$ & 2 & $0.718(0.051)$ & $0.692,0.705(0.052,0.052)$ & $0.705,0.718(0.052,0.051)$ & $0.654,0.654,0.667(0.054,0.054,0.053)$ & $0.769,0.795(0.048,0.046)$ & $0.679(0.053)$ \\
\hline & b & 3 & $0.551(0.056)$ & $0.538,0.526(0.056,0.057)$ & $0.577,0.577(0.056,0.056)$ & $0.513,0.577,0.526(0.057,0.056,0.057)$ & $0.718,0.692(0.051,0.052)$ & $0.526(0.057)$ \\
\hline & c & 4 & $0.603(0.055)$ & $0.628,0.615(0.055,0.055)$ & $0.526,0.538(0.057,0.056)$ & $0.603,0.615,0.603(0.055,0.055,0.055)$ & $0.744,0.744(0.049,0.049)$ & $0.615(0.055)$ \\
\hline & $\mathbf{n}$ & 5 & $0.513(0.057)$ & $0.679,0.667(0.053,0.053)$ & $0.654,0.654(0.054,0.054)$ & $0.564,0.590,0.564(0.056,0.056,0.056)$ & $0.744,0.756(0.049,0.049)$ & $0.564(0.056)$ \\
\hline
\end{tabular}


Table 3: Estimates of evolutionary divergence between bovine archetypal WC1.1, bovine CD163A and bovine CD163C-a SRCR domains (Continued)

\begin{tabular}{|c|c|c|c|c|c|c|c|}
\hline d & 6 & $0.500(0.057)$ & $0.577,0.564(0.056,0.056)$ & $0.577,0.590(0.056,0.056)$ & $\mathbf{0 . 3 4 6}, \mathbf{0 . 4 2 3}, \mathbf{0 . 3 3 3}(0.054,0.056,0.053)$ & $0.679,0.667(0.053,0.053)$ & $0.487(0.057)$ \\
\hline e & 7 & $0.705(0.052)$ & $0.667,0.679(0.056,0.056)$ & $0.692,0.718(0.052,0.051)$ & $0.628,0.641,0.628(0.055,0.054,0.055)$ & $0.526,0.526(0.057,0.057)$ & $0.615(0.055)$ \\
\hline $\mathbf{d}^{\prime}$ & 8 & $0.526(0.057)$ & $0.577,0.577(0.053,0.053)$ & $0.615,0.615(0.055,0.055)$ & $\mathbf{0 . 4 3 6}, \mathbf{0 . 4 2 3}, \mathbf{0 . 3 9 7}(0.056,0.056,0.055)$ & $0.615,0.615(0.055,0.055)$ & $\mathbf{0 . 3 2 1}(0.053)$ \\
\hline
\end{tabular}

Analyses were conducted as described in Table 1. 
activation by Con A. Based on expressed sequence tag (EST) analysis in the NCBI UniGene database http:// www.ncbi.nlm.nih.gov/sites/entrez?db=unigene, it was predicted that bovine CD163c- $\alpha$ is expressed in the intestine and that bovine CD163A is expressed in the intestine and mesenteric lymph node (MLN). Interestingly, we found CD163A to be expressed in all tissues evaluated (Fig. 3A) and not just in intestine and MLN. Surprisingly, we found that $\mathrm{CD} 163 \mathrm{~A}$ is also expressed on $\mathrm{WC} 1^{+}$and $\gamma \delta$ $\mathrm{TCR}^{+}$as well as $\mathrm{WC1}^{-}$and $\gamma \delta \mathrm{TCR}^{-}$cells sorted from $e x$ vivo PBMC (Fig. 3B) indicating that the expression of bovine $\mathrm{CD} 163 \mathrm{~A}$ is not restricted to monocytes and macrophages, as is the case in humans $[5,41]$.

We found that $C D 163 c-\alpha$ transcripts were relatively higher in PBMC, MLN and IELs, than in lung (Fig. 3A), consistent with expression in leukocytes. The CD163c- $\alpha$ family member SCART2 has been shown to be expressed in murine $\gamma \delta \mathrm{T}$ cells [25]. To test the hypothesis that bovine CD163c- $\alpha$ is expressed on a T cell subset separate from the $\mathrm{WC}^{+} \gamma \delta \mathrm{T}$ cell subset, we evaluated the expression of bovine $\mathrm{CD} 163 \mathrm{c}-\alpha$ on $\mathrm{WC1}^{+}, \mathrm{WC1}^{-}, \gamma \delta \mathrm{TCR}^{+}$and $\gamma \delta$ TCR-cells sorted from ex vivo PBMC (Fig. 3B). We found that CD163c- $\alpha$ was preferentially expressed in the
A

B

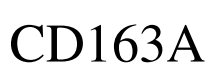

CD163C- $\alpha$

GAPDH

\section{Tissue evaluated}
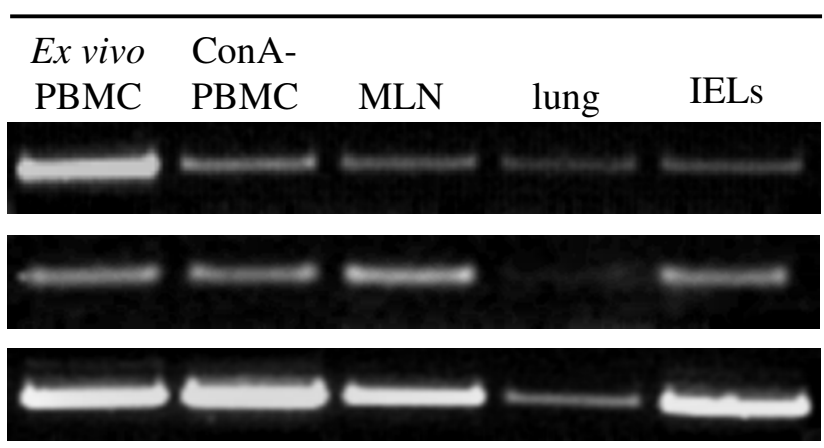

$\begin{array}{lllll}1 & 2 & 3 & 4 & 5\end{array}$

\section{Transcripts amplified}

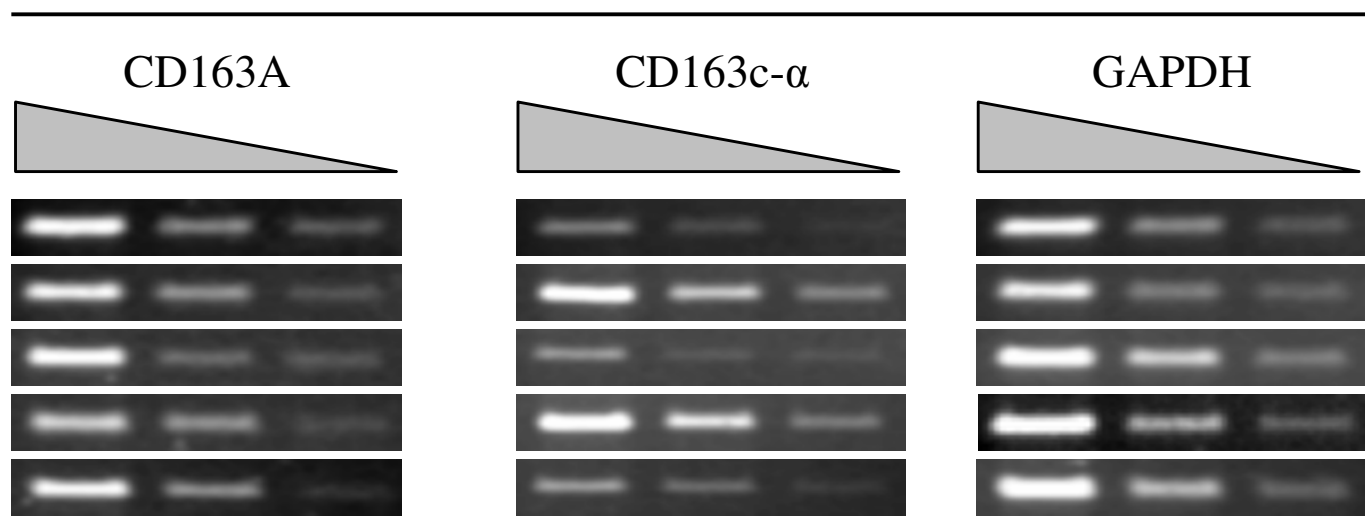

Figure 3 Expression profiles of bovine CD163 genes. (A) Bovine exvivo PBMC (lane 1), ConA-activated PBMC (lane 2), mesenteric lymph node (MLN, lane 3), lung (lane 4) and intestinal epithelial lymphocytes (IELs, lane 5) were evaluated for expression of CD163A and CD163C-a by RT-PCR. GAPDH is shown for comparison. These results are representative of reactions $(n=3)$ performed for at least two animals. (B) Bovine total PBMC, $\gamma \delta T C R^{+} c e l l s, \gamma \delta$ TCR - cells, WC1+ cells, and WC1- cells were evaluated for CD163A, CD163c-a, and GAPDH expression by RT-PCR. Templates were serially diluted by a factor of three. These results are representative of two reactions. 
$\mathrm{WC} 1+$ or $\gamma \delta \mathrm{TCR}+$ cell populations in PBMC, suggesting that it increases the potential receptor repertoire of $\mathrm{WC} 1^{+} \gamma \delta \mathrm{T}$ cells.

\section{Analysis of CD163 and WC1 SRCR domains}

We undertook a phylogenetic analysis of CD163 family members and their closest molecular relative, WC1, with the goal of understanding the evolution and function of WC1 and CD163 family members. We performed multiple alignments of individual SRCR domains in bovine CD163c- $\alpha$ and bovine CD163A with defined SRCR domains from bovine $\mathrm{WC1}$ and human CD163A [1]. The SRCR domains from bovine WC1 and human CD163A have previously been assigned an alphabet letter designation "a", "b", "c", "d", "d' ", "e", "h", "i", "j", or "k" [1]. SRCR domains in bovine CD163c- $\alpha$ and bovine CD163A that clustered in the same clades as these previously designated SRCR domains (Fig. 4A, indicated by asterisks) were assigned the same designation. SRCR domains that clustered in separate clades from the clades containing already designated SRCR domains were assigned the new alphabet letter designations "m", "n" and "l" (Fig. 4A,4B). Phylograms obtained using Bayesian analysis (Fig. 4A) showed that the first SRCR domain of bovine CD163c- $\alpha$ (BtCD163cSRCR1) and the first SRCR domains of CD163c- $\alpha$-like molecules from the duck-billed platypus (OraCD163_4SRCR1, OraCD163_5SRCR1 and OraCD163_7SRCR1) are in the same clade as the first SRCR domain of primate, rodent and canine CD163c- $\alpha$ (designated "m"). The clade containing the fifth SRCR domain (designated "n") in bovine CD163c- $\alpha$ also includes SRCR domains from CD163c- $\alpha$-like molecules from eutherian mammals, the duck-billed platypus and the chicken (Fig. 4A). The second SRCR domain of bovine CD163c- $\alpha$ (BtCD163cSRCR1) clusters in the same clade as other SRCR domains designated "l" from eutherian mammals and the duck-billed platypus (Fig. 4A). SRCR domains that we have designated as "d" are clustered in sister clades to defined "d" SRCR domains by Bayesian analysis: however, their designation as domain "d" is also supported by their position in the protein in reference to other SRCR domains (Fig.4B). Several SRCR domains from chicken CD163 molecules clustered apart from the "d" SRCR domain; although, their identification as "d" SRCR domains is suggested by their position in the protein (e.g. GgCD163_1 SRCR4). These SRCR domains were left undesignated (Fig. 4A,4B). The first six SRCR domains of human CD163b do not reproducibly cluster in the same clade as other defined SRCR domains and were also left undesignated (Fig. 4A,4B). Notably, $\mathrm{CD} 163 \mathrm{~b}$ has thus far been found only in primates and horses. It is also of note that SRCR domain "k", which appears to be diagnostic of CD163A or CD163b, does not appear in any of the annotated genes from the duck-billed platypus or the chicken, suggesting that CD163A or CD163b is not encoded in these animals' genomes. Thus, there appear to be at least 4 types of CD163 family members, not all of which appear in every species, and some of which are duplicated within a species: CD163A, CD163b, CD163c- $\alpha$, and WC1.

Most of the CD163 molecules, especially those with a transmembrane domain, contain the usually membrane proximal "d' " and "e" SRCR domains (Fig. 4B). These domains from chicken and duck-billed platypus cluster together within each species, whereas CD163A "d' " and "e" SRCR domains from eutherian mammals are found in separate sub-clades from CD163b, CD163c- $\alpha$, and WC1 "d' " and "e" SRCR domains from eutherian mammals (Fig. $4 \mathrm{~A})$.

\section{Relationship of CD163c- $a$ and WC1}

The relationship of CD163c- $\alpha$ to WC1 is particularly intriguing since $\mathrm{WC} 1$ expression is restricted to $\gamma \delta \mathrm{T}$ cells and $\mathrm{CD} 163 \mathrm{c}-\alpha$ expression is enriched in $\mathrm{WC} 1+\gamma \delta \mathrm{T}$ cells (Fig. 3B). When we performed a multiple SRCR domain alignment and phylogenetic tree analysis of CD163 proteins across multiple species, we found that the SRCR domain structure and organization of bovine CD163c- $\alpha$ (m-l-b-c-n-d-e-d') is most similar to CD163c- $\alpha$ from other eutherian mammalian species, such as human, chimpanzee, dog, and mouse and rat. The SRCR domains "m" and "l" and " $\mathrm{n}$ " were unique to CD163c- $\alpha$ molecules and were not found to occur in bovine or swine WC1, nor did they occur in the other CD163 family members CD163A or human CD163b (Fig. 4A,4B). Domains "m", "l", and " $\mathrm{n}$ " clustered in separate clades than the WC1 domain "a", as well as from the first six SRCR domains from CD163b and SRCR domains "h", "i", "j", and "k" from CD163A (Fig. 4A,4B).

The chicken and the duck-billed platypus possess more CD163 genes than primates, dogs or rodents, displaying a diverse repertoire more similar to that seen with WC1 genes in the artiodactyls. The chicken possesses at least eighteen CD163 genes while the duck-billed platypus has at least ten CD163 genes. Seven of the chicken CD163 genes and three of the duck-billed platypus CD163 genes contained SRCR domains that clustered in the clade containing WC1 SRCR domain "a" (Fig. 4A). This is notable because domain "a" is the source of most of the diversity in WC1 family members and is thus thought to be the most likely SRCR domain to be responsible for WC1 isoform-specific function [31]. Chicken CD163_3 and platypus CD163_2 were the closest to bovine WC1 in extracellular SRCR organization, with SRCR domain organization of (a-b-c-a-b-c-x-e-d') and (a-c-d-d'), respectively, compared to the bovine WC1 SRCR domain organization of (a-b-c-d-e-d-b-c-d-e-d') (Fig. 4B). Six chicken CD163 proteins show a hybrid SRCR domain 
A

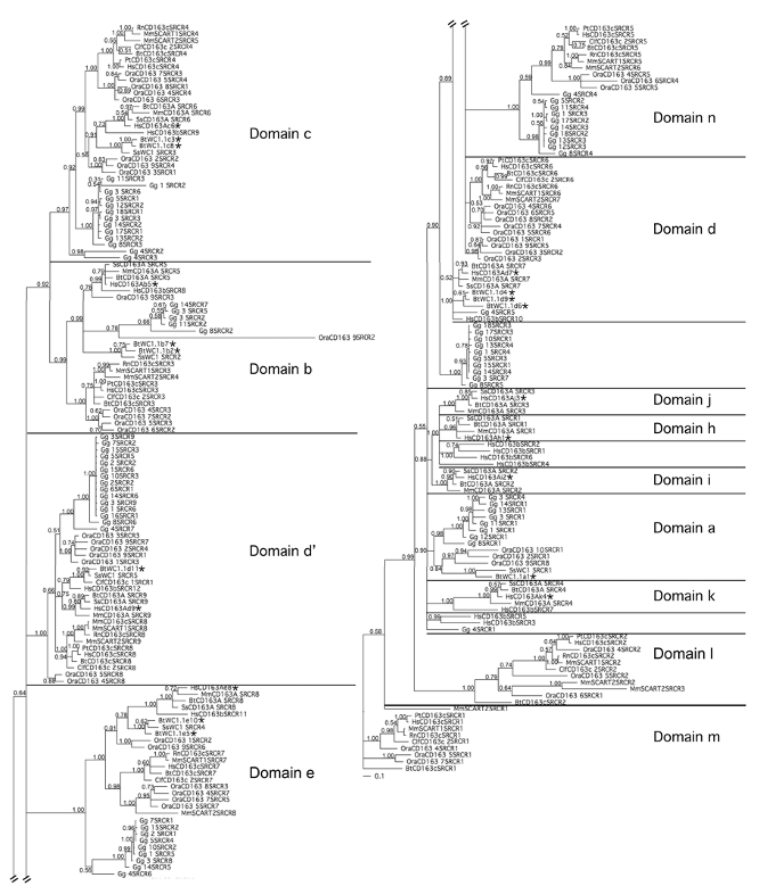

B

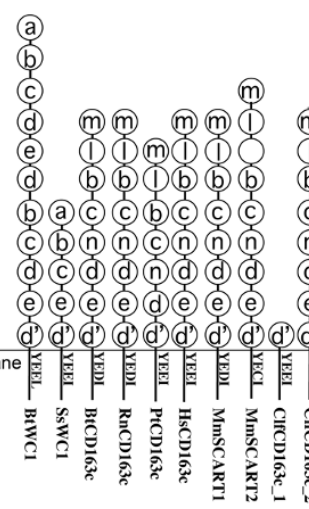

(a)-(b)-(C)-(a)

(a)-(a)-(n)

(a) (c) - -1

(c) (1) - -

(c) (n)

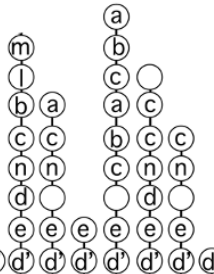

(a)

8

b) c (c)

(a) (a)

(b) (c)

(n)

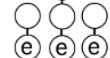

(d) (c) (d) (d) (d)

(h) (h)

(i) (i) (i)

(1) (1) (1)

(b) (k) (k) (1) Extracellular

(c) (b) (b) (b) domain

Figure 4 CD163 family member SRCR domain organization and cytoplasmic tyrosine-based motifs. >(A) CD163 family members from multiple species were identified by BLAST searches with bovine WC1, CD163A and CD163c-a SRCR and cytoplasmic domains. The evolutionary history of 242 taxa was inferred, using MrBayes3.2 to approximate the posterior probabilities of trees, shown at branch nodes [65]. SRCR domains clustering in a clade with pre-defined SRCR domains (asterisks) were identified and SRCR domains clustered together, but not in association with known SRCR domains, were assigned a new letter designation [1]. Rattus norvegicus (Rn) CD163c-a, Pan troglodytes (Pt) CD163c-a, Canis lupus familiaris (Clf) CD163C_1 and ClfCD163c_2, Gallus gallus (Gg) CD163_1 through GgCD163_18, and Ornithorhynchus anatinus (Ora) CD163_1 through OraCD163_10 are predicted from genomic sequence; Bos taurus (Bt) WC1, Sus scrofa (Ss) WC1, Homo sapiens (Hs) CD163c-a (partial cDNA, corrected from genomic sequence), Mus musculus (Mm) SCART1, MmSCART2, HsCD163A and HsCD163b cDNA have been isolated. (B) Summary of CD163 family member SRCR domain organization and cytoplasmic tyrosine based motifs. SRCR domain assignments were made as shown in Fig. 4A, with confirmation by analysis utilizing the Neighbor-Joining algorithm with the JTT model (data not shown). CD163 family members with transmembrane domains are shown with the plasma membrane and location of the transmembrane domains represented by the horizontal line. Tyrosine-based signalling motifs similar to that found in BtWC1 are shown [35]. CD163 family members without transmembrane domains are shown horizontally, with the N-terminus on the left. 
organization that is intermediate between $\mathrm{WC1}$ and CD163c- $\alpha$, with the SRCR domain "a" diagnostic of WC1 and SRCR domain "n" diagnostic of CD163c- $\alpha$. For example, chicken CD163_1 and CD163_8 possess a N-terminal domain "a" characteristic of WC1 but an SRCR domain cassette (c-n-d-e-d') characteristic of CD163c- $\alpha$. In contrast, CD163 molecules from the duck-billed platypus contain either the WC1- diagnostic domain "a", or CD163c- $\alpha$-diagnostic domains "m","l", or "n", but not both.

The consensus group B SRCR domain contains eight cysteines, with disulfide bonds formed between the first and fourth, the second and seventh, the third and eighth, and the fifth and sixth cysteines [42]. Some of the SRCR domains lack the second and/or the seventh cysteine, which results in a predicted SRCR domain with only three disulfide bonds rather than four disulfide bonds. However, MmSCART2_SRCR3 (missing C2, C4 and C7), Gg_1SRCR2 (missing C5, C7, and C8), Gg_4SRCR7 (missing C7 and C8), Gg_5SRCR7 (missing C7 and C8), OraCD163_3SRCR2 (missing $\mathrm{C} 6$ and C7), OraCD163_7SRCR4 (missing C1), OraCD163_9SRCR2 (missing C2, C6, and C7), and OraCD163_6SRCR4 (missing $\mathrm{C} 2, \mathrm{C} 6$, and $\mathrm{C} 7$ ) are missing additional cysteines resulting in SRCR-like domains with only one to three potential disulfide bonds. It is not known how these changes will affect SRCR domain structure and function.

\section{Relationship of cytoplasmic sequences}

Several of the WC1-like or CD163- $\alpha$-like molecules from chicken or duck-billed platypus do not have transmembrane or cytoplasmic domains; although, they are predicted open reading frames from genomic sequence and may not be complete. The cytoplasmic domain of chicken CD163_14, defined as being C-terminal to a transmembrane domain, is unusual in that it is not similar in sequence to other CD163 family members, but instead contains a SRCR domain (Fig. 4B). The cytoplasmic domains of bovine or human CD163A or human CD163b do not have any significant sequence identity with the cytoplasmic domains of CD163c- $\alpha$-like or WC1-like molecules; although bovine and human CD163A have the tyrosine-based motif YREM in their cytoplasmic domains (Fig. 4B). We performed multiple amino acid alignment and phylogenetic tree analysis of the other cytoplasmic domains of CD163c- $\alpha$-like and WC1 molecules and found that the cytoplasmic domains from canine ClfCD163_1, chicken and platypus CD163 molecules cluster more closely with the cytoplasmic domains of bovine and swine WC1, than with the cytoplasmic domains of canine ClfCD163_2, primate, bovine, and rodent CD163c- $\alpha$ (Fig. 5A).

Strikingly, all CD163c- $\alpha$-like molecules from primate, canine, rodent, bovine, monotreme and bird species share a $\mathrm{Y}-(\mathrm{Q} / \mathrm{E})-(\mathrm{D} / \mathrm{C} / \mathrm{E})-(\mathrm{I} / \mathrm{L})$ motif with $\mathrm{WC1}$, with the exception of chicken CD163_15, which has a threonine in place of the isoleucine or leucine (Fig. 5B). Phosphorylation of the YEEL tyrosine motif in $\mathrm{WC} 1$ is required for its potentiation of $\mathrm{T}$ cell activation, suggesting that WC1 and CD163c- $\alpha$ may signal via the same mechanism [35].

\section{Discussion}

Many genes that have been predicted to belong to the CD163 family have been erroneously classified as CD163A or CD163b homologues in their Entrez Gene reports. For example, ClfCD163_2, RnCD163c- $\alpha$ and MmSCART1 are referred to as similar to M160 or CD163L1, which are alternative names for CD163b, despite their greater similarity to $C D 163 \mathrm{c}-\alpha$ in their SRCR identity and organization and in their cytoplasmic domain sequence. GgCD163_10 is referred to as CD5like, despite showing greater sequence similarity to CD163c- $\alpha$ than CD5. Other genes from the chicken and platypus that are most similar to CD163c- $\alpha$ and WC1 are referred to as similar to CD163v2 and CD163v3, which are names for alternatively spliced isoforms of CD163A. It has been speculated that the plethora of CD163 molecules in the platypus are CD163A homologues important for regulating blood serum levels of free hemoglobin, instead of CD163c- $\alpha$ or WC1 homologues, which are more likely to be involved in the immune response [43]. In this study, we show that these genes encode CD163c- $\alpha$, WC1, or CD163c- $\alpha /$ WC1-like proteins, based on the sequence of their SRCR and/or cytoplasmic domains. Genes coding for WC1-like proteins in non-artiodactyls have not been previously identified. SRCR domains "e " and "d' " (Fig. 4A) and cytoplasmic domains (Fig. 5A) that are common to many CD163 molecules across species cluster in sub-clades characterized by eutherian mammalian, platypus or chicken origin, suggesting that gene conversion in multi-gene families over millions of years of evolution has driven homogeneity [44]. Artiodactyls, platypus and chicken all display an expansion of WC1/ CD163c- $\alpha$-like genes (Fig. 6). The platypus and the chicken do not have a CD163A gene, suggesting that CD163A has evolved since the divergence of eutherian mammals from monotremes. In contrast, eutherian mammals have one CD163A gene and non-artiodactyl eutherian mammals have a maximum of two CD163c- $\alpha$ genes. This suggests that expression of multiple WC1/ $\mathrm{CD} 163 \mathrm{c}-\alpha$ genes is the ancestral state and that eutherian mammals other than artiodactyls have lost multiple WC1/CD163c- $\alpha$ genes, since mammals diverged from the sauropsid lineage leading to birds and reptiles 315 million years ago [43]. In a similar finding, the platypus, sheep and cow share an expansion of the cathelicidin antimicrobial peptide gene family, whereas primates and rodents have only a single cathelicidin gene [45]. The pri- 


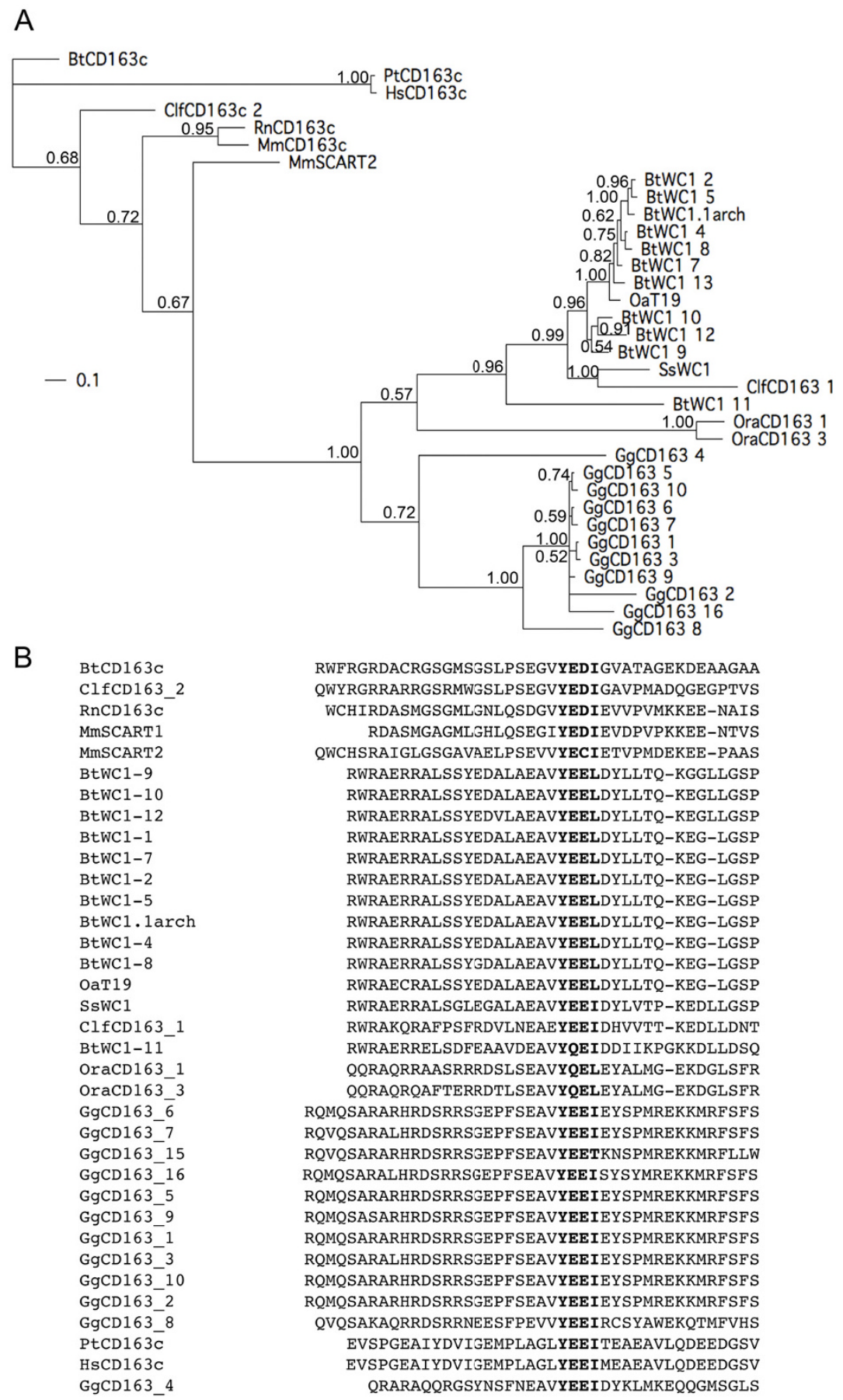

Figure 5 WC1 and CD163ca tyrosine-based motifs in the cytoplasmic domain. (A)Cytoplasmic domains were determined by ascertaining the transmembrane domain, using the DAS transmembrane server [70]. Proteins are labelled as described in Fig. 4, with the addition of bovine WC1 cytoplasmic domains [31]. The evolutionary history of 34 taxa was inferred using Bayesian analysis in MrBayes3.2 [65]. Markov chain Monte Carlo analysis was performed for 830,000 cycles, using 2 runs of 4 chains each, a temperature setting of 0.2 , and an amino acid mixed model to approximate the posterior probabilities of trees, shown at branch nodes. The average standard deviation of split frequencies was 0.01 , which was diagnostic of convergence at $<0.05$. (B)Multiple alignment of the amino acids surrounding the tyrosine motif phosphorylated in WC1 (bold) with similar amino acid sequences from CD163 family members [35]. 


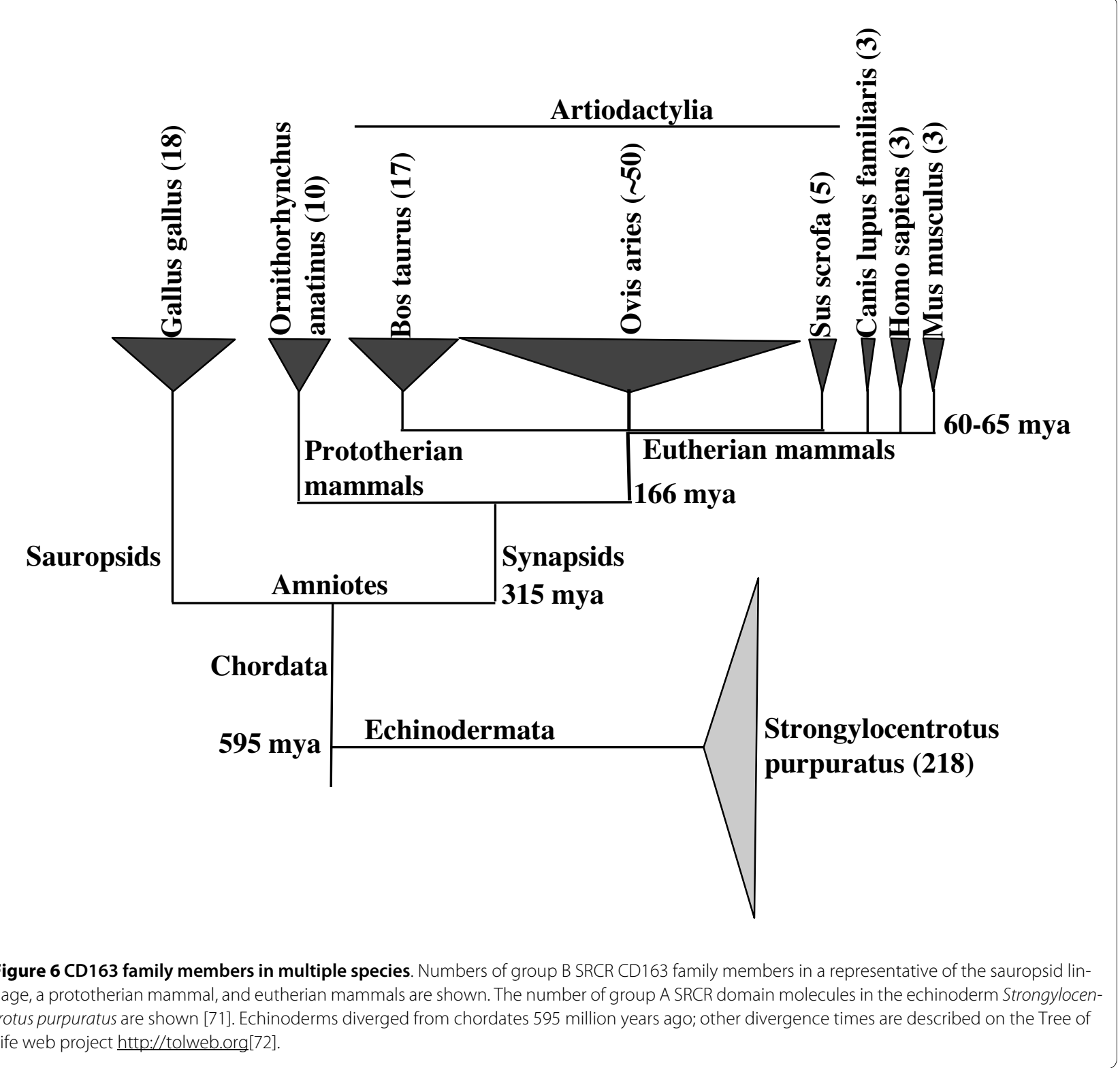

mate or rodent cathelicidin must function equivalently to the plethora of cathelicidins in the platypus or ruminants; analogously, the one or two CD163c- $\alpha$ molecules in nonartiodactyl eutherian mammals may fulfil a function like that of $\mathrm{WC} 1$, in regulating the $\gamma \delta \mathrm{T}$ cell response.

Chickens, cattle and sheep are known to have a high percentage of $\gamma \delta \mathrm{T}$ cells in their peripheral blood. They are referred to as " $\gamma \delta \mathrm{T}$ cell high" species. In contrast, mice and humans have lower numbers of $\gamma \delta \mathrm{T}$ cells in their peripheral blood and are referred to as " $\gamma \delta \mathrm{T}$ cell low" species [46]. It is not known whether the duck-billed platypus is a $\gamma \delta \mathrm{T}$ cell high or $\gamma \delta \mathrm{T}$ cell low species, but it does possess $\gamma \delta \mathrm{T}$ cells [47]. We show that the chicken and platypus have multiple CD163c- $\alpha$ /WC1-like genes, a circumstance that is similar to the multiple WC1 genes in the genomes of the artiodactyls. We hypothesize that a diverse array of CD163c- $\alpha$ /WC1 SRCR transmembrane receptors conveys a selective advantage to the immune response to pathogens by $\gamma \delta \mathrm{T}$ cells and that WC1 and CD163c- $\alpha$ genes have been conserved because they play an important role in the response to pathogens.

Phosphorylation of the second tyrosine in the WC1 cytoplasmic domain is required for WC1-mediated potentiation of $\mathrm{T}$ cell activation though the TCR, thus, the conservation of this motif in WC1-like and CD163c$\alpha$-like genes over millions of years of evolution supports our hypothesis that CD163c- $\alpha$ plays a role similar to WC1 as a co-receptor to an activating receptor [35]. In contrast, it is unknown if the tyrosine-based motif YREM in CD163A of human or cattle is a phosphorylation target 
or whether it participates in membrane proximal signaling by CD163A after ligation of this receptor. Phosphorylation of CD163A by the serine/threonine kinases casein kinase II and protein kinase $\mathrm{C}-\alpha(\mathrm{PKC}-\alpha)$ is tied to cytokine production induced by CD163A cross-linking [19]. Detection of transcripts for bovine CD163A in sorted WC1 ${ }^{+}$and $\gamma \delta^{+} \mathrm{T}$ cells, as well as in tissues containing monocytes and macrophages, suggests that bovine CD163A may play a role in the regulation of the $\gamma \delta^{+} \mathrm{T}$ cell immune response, either through activation of transmembrane CD163A or proteolytic cleavage and release of soluble CD163A.

The characterization of the extracellular SRCR structure of WC1 and CD163 family members may help to isolate their ligands, which in turn would help us to better understand their role in the $\gamma \delta \mathrm{T}$ cell response. The role of $\mathrm{WC} 1$ and the proposed role for $\mathrm{CD} 163 \mathrm{c}-\alpha$ are consistent with other group B SRCR family transmembrane receptors expressed on T cells, such as CD5 and CD6. CD6 binds to the protein ALCAM/CD166 [48]. CD5 has been shown to bind to various proteins, including CD72, a 40-80 kDa glycoprotein expressed on murine B splenocytes and activated T cells, a human $150 \mathrm{kDa}$ glycoprotein expressed on peripheral blood monocytes, certain $\mathrm{IgV}_{\mathrm{H}}$ framework sequences and a bovine $200 \mathrm{kDa}$ protein expressed on activated B cells [49-54]. Ligation of CD5 or CD6 affects responses through the $\mathrm{T}$ cell receptor and $\mathrm{B}$ cell signaling and lymphocyte activation [55,56]. It is known that SRCR molecules also bind to molecules other than proteins; for example, the group B SRCR molecules $\mathrm{Sp} \alpha, \mathrm{CD} 6, \mathrm{DMBT} 1$ and CD163A bind to bacteria and Sp $\alpha$ and CD6 specifically bind to the bacterial products lipoteichoic acid (LTA) and lipopolysaccharide (LPS) $[1,13,14,39,57]$. The SRCR domains in WC1 or bovine CD163c- $\alpha$ do not have the bacteria-binding motif found in multiple SRCR domains of DMBT1 [58]. However, the requirement for expression of specific $\mathrm{WC} 1$ receptors for the $\gamma \delta \mathrm{T}$ cell response to the bacteria Leptospira (Wang F, Herzig CTA, Hsu H, Chen C, Baldwin CL, Telfer JC: Scavenger receptor WC1 contributes to the $\gamma \delta \mathrm{T}$ cell responses to Leptospira, submitted) suggests that WC1/ CD163c- $\alpha$ could recognize pathogen-associated molecules or a protein whose expression is induced by exposure to Leptospira. Although the ligands for $\mathrm{WC} 1$ and CD163c- $\alpha$ are unknown, domains 9 (d) and 11 (d') of bovine WC1 interact with an unknown molecule on the surface of macrophages or dendritic cells [59]. In contrast, another CD163 family member, CD163A, is known to bind haptoglobin-hemoglobin complexes and TWEAK through its third SRCR domain ("j") and to bacteria or a molecule on erythroblasts via its second SRCR domain ("i") [10-13]. Neither of these domains occurs in either WC1 or CD163c- $\alpha$, suggesting that CD163c- $\alpha$ ligation could be mediated by its unique domains "m", "l", or "n", and that it does not bind to haptoglobin-hemoglobin complexes. Since most of the diversity of bovine WC1 is found in domain "a", it is a reasonable candidate for the ligand-binding domain of the WC1 multi-gene family, which confers diversity on the $\gamma \delta \mathrm{T}$ cell response to pathogens.

\section{Conclusions}

We have annotated the genes encoding CD163c- $\alpha$ and CD163A in cattle and shown that bovine CD163A is expressed in tissues containing monocytes and macrophages, as well as in sorted $\gamma \delta \mathrm{T}$ cells. The expression of bovine $\mathrm{CD} 163 \mathrm{c}-\alpha$ is enriched in $\mathrm{WC1} 1^{+} \gamma \delta \mathrm{T}$ cells and it shares the conserved tyrosine motif necessary for WC1 signalling in T cells, implying that it functions similarly to WC1 in acting as a co-receptor for the $\gamma \delta$ TCR. We have characterized CD163c- $\alpha$ and WC1/CD163c- $\alpha$ gene products in multiple species, correcting the incorrect assignment of many of them as CD163A gene products. The expansion of WC1, CD163c- $\alpha$ and WC1/CD163c- $\alpha$ genes is correlated with a high level of $\gamma \delta \mathrm{T}$ cells in the peripheral blood of species separated by approximately 300 million years of evolution, suggesting that a diverse array of these molecules conveys a selective advantage to the $\gamma \delta \mathrm{T}$ cell response. Future studies will address the significant questions of both the signalling potential of CD163c- $\alpha$ and CD163A in $\gamma \delta \mathrm{T}$ cells and the identification of ligands for $\mathrm{CD} 163 \mathrm{c}-\alpha / \mathrm{WC} 1$ molecules.

\section{Methods}

\section{Genome annotation}

In conjunction with the Bovine Genome Sequencing Consortium http://genomes.arc.georgetown.edu/drupal/ bovine/, manual annotation of the CD163 genes was performed using the Apollo Genome Annotation and Curation Tool, version 1.6.5 and the bovine genome assembly Btau_3.1 [60]. Putative CD163 genes were identified by performing a BLAST search with orthologous mouse and human genes against the Bovine Official Gene Set (called GLEAN). The predicted gene models identified from the search included GLEAN_00453 for CD163A and GLEAN_14183 for CD163c- $\alpha$. These were analyzed using the Apollo software and annotated based on available EST evidence and BLAST search results.

\section{Sequence analyses}

Nucleotide sequences were aligned and consensus sequences were created using BioEdit version 7.0.5.3 [61]. Exon/intron structure schematics were based on alignments of cDNA and genomic DNA sequence using SIM4 and visualization with LalnView http://pbil.univ-lyon1.fr/ software/lalnview.html[62].

Amino acid sequences used for comparison in phylogenetic analyses and their accession numbers are described 
in Additional file 1, Table S1. SRCR domains were identified according to the group B SRCR consensus and compared to HsCD163A, HsCD163c- $\alpha$, BtWC1, HsDBMT1, HsCD5, and HsCD6 [42]. Molecules containing group B SRCR domains clustering with CD163 family members were defined as CD163 family members; molecules containing group A SRCR domains or SRCR group B domains clustering with HsDBMT1, HsCD5 and HsCD6 were excluded from analysis. Genomic WC1 cytoplasmic domain sequences used for comparison here have been previously described [31]. Multiple sequence alignments were performed using Clustal X 2.0.8 [63]. Pairwise and multiple alignment penalties for gaps were 10.0, 0.10 for gap extension and Gonnet 250 for protein weight matrix. Alignments were refined in MacClade 4.08. Phylogenetic trees were created using the Neighbor-Joining algorithm in MEGA4 and Bayesian analysis in MrBayes3.2 [64,65]. For Bayesian analysis, 2 runs with 3 cold chains and 1 heated chain each were done. An amino acid mixed model was used to approximate the posterior probabilities of trees. The 242-taxa SRCR domain alignment was run independently three times, with temperature settings of $0.15,0.2$, and 0.25 , for $2.6,2.0$, and 2.5 million generations respectively. Trees were sampled every 100 generations and the burnin fraction was 0.5. The convergence diagnostic used was the average standard deviation of split frequencies, which were $<0.05(0.0427,0.031$, and $0.030)$ for the three runs. The consensus trees from the three runs had the same overall topology. The consensus tree from the run set to temperature 0.25 and 2.5 million generations (average standard deviation of split frequencies 0.030 , average potential scale reduction factor 1.016) is shown in this paper. The 34-taxa cytoplasmic domain alignment was run once with a temperature setting of 0.2 for 830,000 generations. Trees were sampled every 100 generations and the burnin fraction was 0.25 . The average standard deviation of split frequencies was 0.01 and the average potential scale reduction factor was 1.003. Phylograms were visualized using TreeView X 0.5.0 [66].

\section{Animals, cells and tissues}

Belted Galloway cattle of between 1 and 2 years of age were housed at the University of Massachusetts Amherst according to institutional and USDA guidelines. Animal protocols were approved by the University of Massachusetts Amherst institutional animal care and use committee. Blood was obtained via jugular venipuncture and collected into a solution of heparin. Peripheral blood mononuclear cells (PBMC) were isolated from blood via density gradient centrifugation over Ficoll-Paque ${ }^{\mathrm{TM}}$ PLUS (GE Healthcare Bio-Sciences, Piscataway, NJ) by standard techniques. Culture medium consisted of RPMI 1640 (Invitrogen, Carlsbad, CA), 10\% heat-inactivated FBS, 2 $\mathrm{mM} \mathrm{L}$-glutamine, $50 \mu \mathrm{g} / \mathrm{ml}$ gentamicin, and $50 \mu \mathrm{M} 2$-ME.
PBMC were cultured at $2.5 \times 10^{6}$ cells $/ \mathrm{ml}$ with Concanavalin (ConA $1.0 \mu \mathrm{g} / \mathrm{ml}$; Sigma-Aldrich, St. Louis, MO) at $37^{\circ} \mathrm{C}$ with $5 \% \mathrm{CO}_{2}$ in air for 3 days where indicated. For evaluation of $\mathrm{CD} 163$ expression in intestine, intraepithelial lymphocytes (IELs) were isolated from the ileum of two-month old cattle using nonenzymatic methods [67]. IELs were stained for cell surface differentiation molecules, fixed in $1 \%$ paraformaldehyde, and analyzed via flow cytometry (LSR II, BD Biosciences, San Jose, CA) using the following primary monoclonal antibodies (mAbs): CC15 (pan-WC1; Serotec, Raleigh, NC), GB21A ( $\delta$ TCR; VMRD, Pullman, WA), and IL-A12 (CD4;) [68]. Secondary antibodies used were isotype-specific polyclonal goat anti-mouse Ig conjugated with fluorescein isothiocyanate (FITC) (Southern Biotechnology, Birmingham, AL). Flow cytometric data was analyzed using FlowJo version 7.2.2 (Tree Star, Ashland, OR).

Purified $\gamma \delta \mathrm{T}$ cells and $\mathrm{WC} 1+\gamma \delta \mathrm{T}$ cells were obtained from ex vivo PBMC by magnetic bead sorting (MACS; Miltenyi Biotec, Auburn, CA). Cells were suspended in PBS containing 6\% heat-inactivated horse serum and incubated with monoclonal antibodies (mAbs) GB21A or CC15 for 20 min on ice, washed twice with PBS containing $0.5 \%$ bovine serum albumin and $2 \mathrm{mM}$ EDTA and resuspended in the same along with goat anti-mouse IgG microbeads (Miltenyi Biotec) following the manufacturer's instructions. Cells were purified over pre-cooled MS-separation columns (Miltenyi Biotec); the positive and negative fractions were collected and each was passed over an additional separation column in order to optimize purity. Purity was assessed by flow cytometry and was found to be $99.6 \%$ for $\gamma \delta \mathrm{T}$ cells, $98.1 \%$ for $\gamma \delta \mathrm{T}$ cell-depleted cells, $95.5 \%$ for $\mathrm{WC}^{+} \gamma \delta \mathrm{T}$ cells and $92.7 \%$ for $\mathrm{WC1}^{+} \gamma \delta \mathrm{T}$ cell-depleted cells.

\section{RNA isolation and RT-PCR}

Pelleted ex vivo or ConA-activated PBMC, sorted cells, and IELs were resuspended in TRIzol (Invitrogen). MLN and lung tissue samples frozen in TRIzol were thawed and homogenized. RNA was isolated according to the manufacturer's protocol. For RNA isolation from sorted cells, glycogen (Invitrogen) was added to the aqueous phase prior to RNA precipitation. Reverse transcription (RT) was performed using $1 \mu \mathrm{g}$ of total RNA, oligo dT primers and AMV reverse transcriptase (AMV RT kit; Promega, Madison, WI). Prior to RT reactions, RNA derived from MLN and lung was treated using RQ1 RNase-Free DNase (Promega) according to the manufacturer's protocol. $2 \mu \mathrm{l}$ of cDNA was used as template in subsequent PCR reactions.

Primer pair sequences used to obtain CD163A and CD163c- $\alpha$ cDNA sequences are as follows: (1) CD163Autr-for 5'-GAG TGG ACA AAC TCA GAA TGG TG and CD163A-rev2 5'-GAG GAA TTA TAT 
AGG TCC AGA TCA TC; (2) CD163A2952-for 5'-CAT ATG GCT CAA TGA AGT GAA GTG and CD163Autrrev 5'-GTG CAT CAC AGG CTT CTT ATT ATG; (3) CD163c2312-for 5'-GTG TGG AGC TCT GGC ACG CTG and CD163c-rev2 5'-CAA TGT CCT CAT AAA CAC CTT CTG; (4) CD163c1938-for 5'-CCT CTG CTC AGA GTC AGT G and CD163c2312-rev 5'-CAG CGT GCC AGA GCT CCA CAC using PCR Master Mix (Promega). Cycling parameters were $30 \mathrm{~s}$ at $94^{\circ} \mathrm{C}, 30 \mathrm{~s}$ at $50^{\circ} \mathrm{C}$ and approximately $1 \mathrm{~min} / \mathrm{kb}$ at $68^{\circ} \mathrm{C}$ for 35 cycles. PCR products were ligated in the pCR2.1 vector (Invitrogen) and sequenced (GeneWiz, South Plainfield, NJ) using the T7 forward and M13 reverse primers, as well as the following sequence specific primers, where applicable: CD163Aseq2-for 5'-CCA ATC TGG TTT GAT GAT CTG GTA; CD163Aseq3-for 5'-TCT GAC TTC TCT CTG GAA TCG; CD163Aseq4-for 5'-CAG AAC TGC AGG CAT AAG GAG; CD163Aseq1-rev 5'-GCT GCC CCA AGC TCC GTT G; CD163Aseq2-rev 5' - CAT TCG TGA TGT CTG CAC TG; CD163A1824-rev 5'-CAT GTC CCA GTG AGA GTT GCA GAG.

For expression analysis PCR Master Mix (Promega) was used. Primer sequences were as follows: GAPDH-for 5'GTCATCATCTCTGCACCTTCT; GAPDH-rev 5'ACCACCTTCTTGATCTCATCAT; For CD163A and CD163c- $\alpha$ primer pairs (2) and (3) described above were used, respectively. Cycling parameters were $30 \mathrm{~s}$ at $94^{\circ} \mathrm{C}$, $30 \mathrm{~s}$ at $55^{\circ} \mathrm{C}$ and $1 \mathrm{~min}$ at $68^{\circ} \mathrm{C}$ for 30 cycles (GAPDH) or 35 cycles (CD163A and CD163c). CD163A and CD163c$\alpha$ PCR products were directly sequenced (GeneWiz, South Plainfield, NJ) in order to verify primer specificity.

\section{Additional material}

Additional file $\mathbf{1}$ Table S1. Accession numbers for amino acid sequences used for phylogenetic analysis.

\section{Authors' contributions}

CTAH annotated the bovine CD163 genes, performed the expression analysis and helped prepare the manuscript. WRW supplied the bovine tissues used for the expression analysis. CLB helped in the study coordination and manuscript preparation. JCT conceived of the study, performed the phylogenetic analysis and drafted the manuscript. All authors read and approved the final manuscript.

\section{Acknowledgements}

This work was conducted as part of the Bovine Genome Sequencing Consortium and supported by the National Research Initiative of the USDA CSREES, Grant \#2006-1691 and the Hatch regional genome project. We thank Alexander Hajir for useful discussions.

\section{Author Details}

1 University of Massachusetts Amherst, Department of Veterinary and Animal Sciences, Paige Laboratory, Amherst, MA 01003, USA and 2National Animal Diseases Center, USDA-ARS, Ames, lowa, 50010, USA

Received: 8 September 2009 Accepted: 15 June 2010 Published: 15 June 2010

\section{References}

1. Sarrias MR, Gronlund J, Padilla O, Madsen J, Holmskov U, Lozano F: The Scavenger Receptor Cysteine-Rich (SRCR) domain: an ancient and highly conserved protein module of the innate immune system. Crit Rev Immunol 2004, 24(1):1-37.

2. Kristiansen M, Graversen JH, Jacobsen C, Sonne O, Hoffman HJ, Law SK, Moestrup SK: Identification of the haemoglobin scavenger receptor. Nature 2001, 409(6817):198-201

3. Hogger P, Dreier J, Droste A, Buck F, Sorg C: Identification of the integral membrane protein RM3/1 on human monocytes as a glucocorticoidinducible member of the scavenger receptor cysteine-rich family (CD163). J Immunol 1998, 161(4):1883-1890.

4. Schaer DJ, Boretti FS, Hongegger A, Poehler D, Linnscheid P, Staege H, Muller C, Schoedon G, Schaffner A: Molecular cloning and characterization of the mouse CD163 homologue, a highly glucocorticoid-inducible member of the scavenger receptor cysteinerich family. Immunogenetics 2001, 53(2):170-177.

5. Sulahian TH, Hogger P, Wahner AE, Wardwell K, Goulding NJ, Sorg C, Droste A, Stehling M, Wallace PK, Morganelli PM, Guyre PM: Human monocytes express CD163, which is upregulated by IL-10 and identical to p155. Cytokine 2000, 12(9):1312-1321.

6. Matthews KE, Mueller SG, Woods C, Bell DN: Expression of the hemoglobin-haptoglobin receptor CD163 on hematopoietic progenitors. Stem Cells Dev 2006, 15(1):40-48.

7. Fabriek BO, Dijkstra CD, van den Berg TK: The macrophage scavenger receptor CD163. Immunobiology 2005, 210(2-4):153-160.

8. Philippidis P, Mason JC, Evans BJ, Nadra I, Taylor KM, Haskard DO, Landis $\mathrm{RC}$ : Hemoglobin scavenger receptor CD163 mediates interleukin-10 release and heme oxygenase- 1 synthesis: antiinflammatory monocyte-macrophage responses in vitro, in resolving skin blisters in vivo, after cardiopulmonary bypass surgery. Circ Res 2004 94(1):119-126

9. Hogger P, Sorg C: Soluble CD163 inhibits phorbol ester-induced lymphocyte proliferation. Biochem Biophys Res Commun 2001, 288(4):841-843.

10. Madsen M, Moller HJ, Nielsen MJ, Jacobsen C, Graversen JH, van den Berg T, Moestrup SK: Molecular characterization of the haptoglobin hemoglobin receptor CD163. Ligand binding properties of the scavenger receptor cysteine-rich domain region. J Biol Chem 2004, 279(49):51561-51567.

11. Bover LC, Cardo-Vila M, Kuniyasu A, Sun J, Rangel R, Takeya M, Aggarwal $B B$, Arap W, Pasqualini R: A previously unrecognized protein-protein interaction between TWEAK and CD163: potential biological implications. J Immunol 2007, 178(12):8183-8194.

12. Fabriek $B O$, Polfliet MM, Vloet RP, van der Schors RC, Ligtenberg AJ, Weaver LK, Geest C, Matsuno K, Moestrup SK, Dijkstra CD, van den Berg TK: The macrophage CD163 surface glycoprotein is an erythroblast adhesion receptor. Blood 2007, 109(12):5223-5229.

13. Fabriek BO, van Bruggen R, Deng DM, Ligtenberg AJ, Nazmi K, Schornagel K, Vloet RP, Dijkstra CD, van den Berg TK: The macrophage scavenger receptor CD163 functions as an innate immune sensor for bacteria. Blood 2009, 113(4):887-892.

14. Sarrias MR, Farnos M, Mota R, Sanchez-Barbero F, Ibanez A, Gimferrer I, Vera J, Fenutria R, Casals C, Yelamos J, Lozano F: CD6 binds to pathogenassociated molecular patterns and protects from LPS-induced septic shock. Proc Natl Acad Sci USA 2007, 104(28):11724-11729.

15. Law SK, Micklem KJ, Shaw JM, Zhang XP, Dong Y, Willis AC, Mason DY: A new macrophage differentiation antigen which is a member of the scavenger receptor superfamily. Eur J Immunol 1993, 23(9):2320-2325.

16. Ritter M, Buechler C, Langmann T, Orso E, Klucken J, Schmitz G: The scavenger receptor CD163: regulation, promoter structure and genomic organization. Pathobiology 1999, 67(5-6):257-261.

17. Nielsen MJ, Madsen M, Moller HJ, Moestrup SK: The macrophage scavenger receptor CD163: endocytic properties of cytoplasmic tail variants. J Leukoc Biol 2006, 79(4):837-845

18. Van den Heuvel MM, Tensen CP, van As JH, Van den Berg TK, Fluitsma DM, Dijkstra CD, Dopp EA, Droste A, Van Gaalen FA, Sorg C, Hogger P, Beelen $\mathrm{RH}$ : Regulation of CD 163 on human macrophages: cross-linking of CD163 induces signaling and activation. J Leukoc Biol 1999, 66(5):858-866

19. Ritter M, Buechler C, Kapinsky M, Schmitz G: Interaction of CD163 with the regulatory subunit of casein kinase II (CKII) and dependence of 
CD163 signaling on CKII and protein kinase C. Eur J Immunol 2001, 31(4):999-1009.

20. Strauss M, Levy AP: Regulation of CD163 associated casein kinase II activity is haptoglobin genotype dependent. Mol Cell Biochem 2008, 317(1-2):131-135

21. Levy AP, Hochberg I, Jablonski K, Resnick HE, Lee ET, Best L, Howard BV: Haptoglobin phenotype is an independent risk factor for cardiovascular disease in individuals with diabetes: The Strong Heart Study. J Am Coll Cardiol 2002, 40(11):1984-1990.

22. Suleiman M, Aronson D, Asleh R, Kapeliovich MR, Roguin A, Meisel SR, Shochat M, Sulieman A, Reisner SA, Markiewicz W, Hammerman H, Lotan R, Levy NS, Levy AP: Haptoglobin polymorphism predicts 30-day mortality and heart failure in patients with diabetes and acute myocardial infarction. Diabetes 2005, 54(9):2802-2806.

23. Gronlund J, Vitved L, Lausen M, Skjodt K, Holmskov U: Cloning of a novel scavenger receptor cysteine-rich type I transmembrane molecule (M160) expressed by human macrophages. J Immunol 2000, 165(11):6406-6415.

24. Holm D, Fink DR, Gronlund J, Hansen S, Holmskov U: Cloning and characterization of SCART1, a novel scavenger receptor cysteine-rich type I transmembrane molecule. Mol Immunol 2009, 46(8-9):1663-1672.

25. Kisielow J, Kopf M, Karjalainen K: SCART scavenger receptors identify a novel subset of adult gammadelta T cells. J Immunol 2008, 181(3):1710-1716.

26. Wijngaard PL, Metzelaar MJ, MacHugh ND, Morrison WI, Clevers HC: Molecular characterization of the WC1 antigen expressed specifically on bovine CD4-CD8- gamma delta T lymphocytes. J Immuno/ 1992, 149(10):3273-3277.

27. Mackay CR, Beya MF, Matzinger P: Gamma/delta T cells express a unique surface molecule appearing late during thymic development. Eur J Immunol 1989, 19(8):1477-1483.

28. O'Keeffe MA, Metcalfe SA, Glew MD, Bowden T, McInnes S, Kimpton WG, Cahill RN, Hein WR, Walker ID: Lymph node homing cells biologically enriched for gamma delta T cells express multiple genes from the T19 repertoire. Int Immunol 1994, 6(11):1687-1697.

29. Walker ID, Glew MD, O'Keeffe MA, Metcalfe SA, Clevers HC, Wijngaard PL, Adams TE, Hein WR: A novel multi-gene family of sheep gamma delta $T$ cells. Immunology 1994, 83(4):517-523.

30. Carr MM, Howard CJ, Sopp P, Manser JM, Parsons KR: Expression on porcine gamma delta lymphocytes of a phylogenetically conserved surface antigen previously restricted in expression to ruminant gamma delta T lymphocytes. Immunology 1994, 81(1):36-40.

31. Herzig CTA, Baldwin CL: Genomic organization and classification of the bovine WC1 genes and expression by peripheral blood gamma delta T cells. BMC Genomics 2009, 10:191.

32. Mackay CR, Maddox JF, Brandon MR: Three distinct subpopulations of sheep T lymphocytes. Eur J Immunol 1986, 16(1):19-25

33. Clevers $H$, MacHugh ND, Bensaid A, Dunlap S, Baldwin CL, Kaushal A, lams K, Howard CJ, Morrison WI: Identification of a bovine surface antigen uniquely expressed on CD4-CD8- T cell receptor gamma/delta+ T lymphocytes. Eur J Immunol 1990, 20(4):809-817.

34. Morrison WI, Davis WC: Individual antigens of cattle. Differentiation antigens expressed predominantly on CD4- CD8- Tlymphocytes (WC1, WC2). Vet Immunol Immunopathol 1991, 27(1-3):71-76.

35. Wang F, Herzig C, Ozer D, Baldwin CL, Telfer JC: Tyrosine phosphorylation of scavenger receptor cysteine-rich WC1 is required for the WC1mediated potentiation of TCR-induced T-cell proliferation. Eur J Immunol 2009, 39(1):254-266.

36. Lahmers KK, Hedges JF, Jutila MA, Deng M, Abrahamsen MS, Brown WC: Comparative gene expression by WC1+ gammadelta and CD4+ alphabeta T lymphocytes, which respond to Anaplasma marginale, demonstrates higher expression of chemokines and other myeloid cell-associated genes by WC1+ gammadelta T cells. J Leukoc Biol 2006, 80(4):939-952.

37. Rogers AN, Vanburen DG, Hedblom EE, Tilahun ME, Telfer JC, Baldwin CL: Gammadelta T cell function varies with the expressed WC1 coreceptor. $\mathrm{J}$ Immunol 2005, 174(6):3386-3393.

38. Vera J, Fenutria R, Canadas O, Figueras M, Mota R, Sarrias MR, Williams DL, Casals C, Yelamos J, Lozano F: The CD5 ectodomain interacts with conserved fungal cell wall components and protects from zymosaninduced septic shock-like syndrome. Proc Natl Acad Sci USA 2009, 106(5):1506-1511.
39. Sarrias MR, Rosello S, Sanchez-Barbero F, Sierra JM, Vila J, Yelamos J, Vives J, Casals C, Lozano F: A role for human Sp alpha as a pattern recognition receptor. J Biol Chem 2005, 280(42):35391-35398.

40. Ligtenberg AJ, Veerman EC, Nieuw Amerongen AV, Mollenhauer J: Salivary agglutinin/glycoprotein-340/DMBT1: a single molecule with variable composition and with different functions in infection, inflammation and cancer. Biol Chem 2007, 388(12):1275-1289.

41. Hogger P, Erpenstein U, Rohdewald P, Sorg C: Biochemical characterization of a glucocorticoid-induced membrane protein (RM3/ 1 ) in human monocytes and its application as model system for ranking glucocorticoid potency. Pharm Res 1998, 15(2):296-302.

42. Rodamilans B, Munoz IG, Bragado-Nilsson E, Sarrias MR, Padilla O, Blanco FJ, Lozano F, Montoya G: Crystal structure of the third extracellular domain of $C D 5$ reveals the fold of a group B scavenger cysteine-rich receptor domain. J Biol Chem 2007, 282(17):12669-12677.

43. Warren WC, Hillier LW, Marshall Graves JA, Birney E, Ponting CP, Grutzner F, Belov K, Miller W, Clarke L, Chinwalla AT, Yang SP, Heger A, Locke DP, Miethke P, Waters PD, Veyrunes F, Fulton L, Fulton B, Graves T, Wallis J, Puente XS, Lopez-Otin C, Ordonez GR, Eichler EE, Chen L, Cheng Z, Deakin JE, Alsop A, Thompson K, Kirby P, et al:: Genome analysis of the platypus reveals unique signatures of evolution. Nature 2008, 453(7192): 175-183.

44. Carson AR, Scherer SW: Identifying concerted evolution and gene conversion in mammalian gene pairs lasting over 100 million years. BMC Evol Biol 2009, 9:156.

45. Zanetti M: Cathelicidins, multifunctional peptides of the innate immunity. J Leukoc Biol 2004, 75(1):39-48.

46. Born W, Cady C, Jones Carson J, Mukasa A, Lahn M, O'Brien R: Immunoregulatory functions of gamma delta T cells. Adv Immunol 1999, 71:77-144

47. Parra ZE, Arnold T, Nowak MA, Hellman L, Miller RD: TCR gamma chain diversity in the spleen of the duckbill platypus (Ornithorhynchus anatinus). Dev Comp Immunol 2006, 30(8):699-710.

48. Bodian DL, Skonier JE, Bowen MA, Neubauer M, Siadak AW, Aruffo A, Bajorath J: Identification of residues in CD6 which are critical for ligand binding. Biochemistry 1997, 36(9):2637-2641.

49. Van de Velde H, von Hoegen I, Luo W, Parnes JR, Thielemans $K$ : The B cell surface protein CD72/Lyb-2 is the ligand for CD5. Nature 1991, 351(6328):662-665.

50. Biancone L, Bowen MA, Lim A, Aruffo A, Andres G, Stamenkovic I: Identification of a novel inducible cell-surface ligand of CD5 on activated lymphocytes. J Exp Med 1996, 184(3):811-819.

51. Bikah G, Lynd FM, Aruffo AA, Ledbetter JA, Bondada S: A role for CD5 in cognate interactions between $T$ cells and $B$ cells, and identification of a novel ligand for CD5. Int Immunol 1998, 10(8):1185-1196.

52. Calvo J, Places L, Padilla O, Vila JM, Vives J, Bowen MA, Lozano F: Interaction of recombinant and natural soluble CD5 forms with an alternative cell surface ligand. Eur J Immunol 1999, 29(7):2119-2129.

53. Pospisil $R$, Fitts MG, Mage RG: $C D 5$ is a potential selecting ligand for $B$ cell surface immunoglobulin framework region sequences. J Exp Med 1996, 184(4):1279-1284

54. Haas KM, Estes DM: The identification and characterization of a ligand for bovine CD5. J Immunol 2001, 166(5):3158-3166.

55. Lozano F, Simarro M, Calvo J, Vila JM, Padilla O, Bowen MA, Campbell KS: CD5 signal transduction: positive or negative modulation of antigen receptor signaling. Crit Rev Immunol 2000, 20(4):347-358.

56. Gimferrer I, Calvo M, Mittelbrunn M, Farnos M, Sarrias MR, Enrich C, Vives J, Sanchez-Madrid F, Lozano F: Relevance of CD6-mediated interactions in T cell activation and proliferation. J Immunol 2004, 173(4):2262-2270.

57. Madsen J, Tornoe I, Nielsen O, Lausen M, Krebs I, Mollenhauer J, Kollender G, Poustka A, Skjodt K, Holmskov U: CRP ductin, the mouse homologue of gp-340/deleted in malignant brain tumors 1 (DMBT1), binds grampositive and gram-negative bacteria and interacts with lung surfactant protein D. Eur J Immunol 2003, 33(8):2327-2336.

58. Bikker FJ, Ligtenberg AJ, End C, Renner M, Blaich S, Lyer S, Wittig R, van't Hof W, Veerman EC, Nazmi K, de Blieck-Hogervorst JM, Kioschis P, Nieuw Amerongen AV, Poustka A, Mollenhauer J: Bacteria binding by DMBT1/ SAG/gp-340 is confined to the VEVLXXXXW motif in its scavenger receptor cysteine-rich domains. J Biol Chem 2004, 279(46):47699-47703.

59. Ahn JS, Konno A, Gebe JA, Aruffo A, Hamilton MJ, Park YH, Davis WC: Scavenger receptor cysteine-rich domains 9 and 11 of WC1 are 
receptors for the WC1 counter receptor. J Leukoc Bio/ 2002, 72(2):382-390.

60. Lewis SE, Searle SM, Harris N, Gibson M, Lyer V, Richter J, Wiel C, Bayraktaroglir L, Birney E, Crosby MA, Kaminker JS, Matthews BB, Prochnik SE, Smithy CD, Tupy JL, Rubin GM, Misra S, Mungall CJ, Clamp ME: Apollo: a sequence annotation editor. Genome Biol 2002, 3(12):RESEARCH0082.

61. Hall TA: BioEdit: a user-friendly biological sequence alignment editor and analysis program for Windows 95/98/NT. Nucl Acids Symp Ser 1999, 41:95-98.

62. Florea L, Hartzell G, Zhang Z, Rubin GM, Miller W: A computer program for aligning a CDNA sequence with a genomic DNA sequence. Genome Res 1998, 8(9):967-974.

63. Larkin MA, Blackshields G, Brown NP, Chenna R, McGettigan PA, McWilliam H, Valentin F, Wallace IM, Wilm A, Lopez R, Thompson JD, Gibson TJ, Higgins DG: Clustal W and Clustal X version 2.0. Bioinformatics 2007, 23(21):2947-2948.

64. Tamura K, Dudley J, Nei M, Kumar S: MEGA4: Molecular Evolutionary Genetics Analysis (MEGA) software version 4.0. Mol Biol Evol 2007, 24(8):1596-1599.

65. Ronquist $F$, Huelsenbeck JP: MrBayes 3 Bayesian phylogenetic inference under mixed models. Bioinformatics 2003, 19(12):1572-1574.

66. Page RD: TreeView an application to display phylogenetic trees on personal computers. Comput Appl Biosci 1996, 12(4):357-358.

67. Koets A, Rutten V, Hoek A, van Mil F, Muller K, Bakker D, Gruys E, van Eden W: Progressive bovine paratuberculosis is associated with local loss of CD4(+) T cells, increased frequency of gamma delta T cells, and related changes in T-cell function. Infect Immun 2002, 70(7):3856-3864.

68. Baldwin CL, Teale AJ, Naessens JG, Goddeeris BM, MacHugh ND, Morrison Wl: Characterization of a subset of bovine T lymphocytes that express BoT4 by monoclonal antibodies and function: similarity to lymphocytes defined by human T4 and murine L3T4. J Immunol 1986, 136(12):4385-4391.

69. Felsenstein J: Confidence limits on phylogenies: An approach using the bootstrap. Evolution 1985, 39:783-791.

70. Cserzo M, Wallin E, Simon I, von Heijne G, Elofsson A: Prediction of transmembrane alpha-helices in prokaryotic membrane proteins: the dense alignment surface method. Protein Eng 1997, 10(6):673-676

71. Hibino T, Loza Coll M, Messier C, Majeske AJ, Cohen AH, Terwilliger DP, Buckley KM, Brockton V, Nair SV, Berney K, Fugmann SD, Anderson MK, Pancer Z, Cameron RA, Smith LC, Rast JP: The immune gene repertoire encoded in the purple sea urchin genome. Dev Bio/ 2006 300(1):349-365.

72. Ayala FJ, Rzhetsky A: Origin of the metazoan phyla: molecular clocks confirm paleontological estimates. Proc Natl Acad Sci USA 1998, 95(2):606-611.

doi: $10.1186 / 1471-2148-10-18$

Cite this article as: Herzig et al., Evolution of the CD163 family and its relationship to the bovine gamma delta T cell co-receptor WC1 BMC Evolutionary Biology 2010, 10:181

Submit your next manuscript to BioMed Centra and take full advantage of:

- Convenient online submission

- Thorough peer review

- No space constraints or color figure charges

- Immediate publication on acceptance

- Inclusion in PubMed, CAS, Scopus and Google Scholar

- Research which is freely available for redistribution

Submit your manuscript at www.biomedcentral.com/submit
C Biomed Central 